\title{
A VIRGINIAMICINA COMO ESTIMULANTE DO CRESCIMENTO DE SUINOS EM RECRIA
}

SACODNA DOVA FERROUGEM GOMES

Engenheira Agrônoma

Orientador: PROF. DR. VALDOMIRO SHIGUERU MIYADA

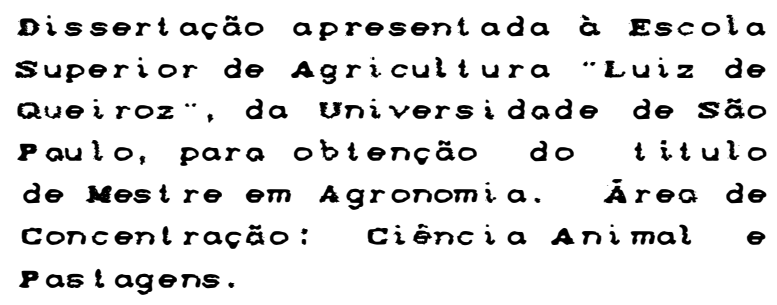

P I R A C I C A B A

Estado de São Paulo - Brasil

outubro - 1991 
Ficha catalográfica preparada pela Seção de Livros da Divisão de Biblioteca e Documentação - PCAP/USP

Gomes, Jacinta Diva Ferrugem

G633v A virginiamicina como estimulante do crescimento de suínos em recria. Piracicaba, 1991.

$54 \mathrm{p}$. ilus.

Diss. (Mestre) - ESALQ

Bibliografia.

1. Estimulante do crescimento 2. Leitão - Crescimento Efeito da virginiamicina 3. Virginiamicina como estimulan te do crescimento I. Escola Superior de Agricultura Luiz de Queiroz, Piracicaba

$\operatorname{CDD} \quad 636.4$ 


\section{A VIRGINIAMICINA COMO ESTIMULANTE DO CRESCIMENTO DE SUINOS EM RECRIA}

DACONTA DOVA FERRUUEM GOMES

Aprovada em 09.12.1991

Comissão julgadora:

Prof. Dr. Valdomiro Shigueru Mi yada ESALQ USP

Prof. Dr. José Fernando Machado Menten

ESALQ USP

Dr. Gustavo Júlio M. M. de Lima

CNPSA EMBRAPA

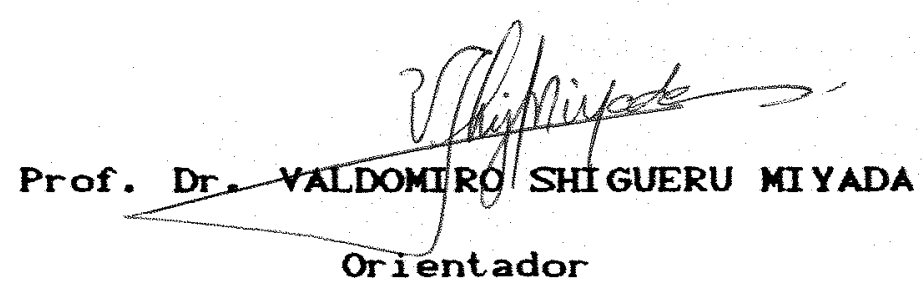


"Ainda que eu falasse a linguagem dos homens, Ainda gue eu falasse a linguagem dos anjos e Ainda que eu possuisse o dom de profetizar. Se não houvesse amor, Eu nada seria".

$A$ Deus e todas as energias superiores de luz, que sempre estiveram do meu lado fortalecendo meus punhos e pernas:

DEDICO

A tão amada e admirada Edy, minha mâe e amiga, que junto a meu pai Francisco, sâo responsáveis por mais esta vitória,

A Walter Rodrigues da Silva, aquele que me comprovou que todo sonho possui sua contraparte real.

OFERECO

A Dr Lia Helena Campos, amiga das horas tão dificeis e tão recompesadoras,

Aos queridos e anados irmãos lacira, hussara, lânio; cunhados Tarciso e Beatriz; sobrinhos Fernanda, Olivia o gue está para chegar; e todos os amigos que acreditaram em meu trabalho 


\section{AGRADECI MENTOS}

-A Marcelo Queiroz Ferreira Barata, por todo apoio. carinho e incentivo.

- Ao Prof. Dr. Valdomiro Shigueru Mi yada, meu orientador, pela oportunidade oferecida.

- Ao Prof. Dr. Roberto Di as de Moraes e Silva e Prof. Dr. José Fernando Machado Menten, pelo apoio.

- As colegas lila Carlota Lopez Preciado e Rosangela Maria Possobon, que auxiliaram no desenvolvimento da etapa experimental.

- Aos funcionarios do Setor de Suinocultura do Departamento de Zootecnia. ESALQUSP, que auxiliaram na condufão do experimento.

- Aos funcionarios do Laboratorio de Bromatologia do Departamento de Zootecnia, ESALQUSP, que auxiliaram na realização das análises bromatológicas.

- A FAPESP - Fundação de Amparo Pesquisa do Estado de Sa Paulo, pela concessão da bolsa de estudo de mestrado e pelo apoio financeiro para a realização deste trabal ho.

- A todos aqueles que direta ou indiretamente contribuiram para a concretização deste trabal ho de pesquisa. 
LISTA DE FIGURAS $\ldots \ldots \ldots \ldots \ldots \ldots \ldots \ldots \ldots \ldots$

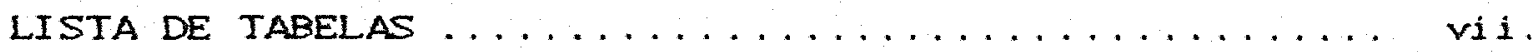

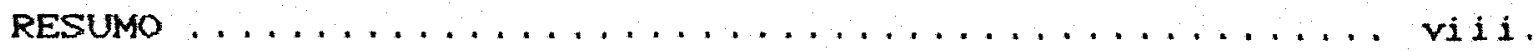

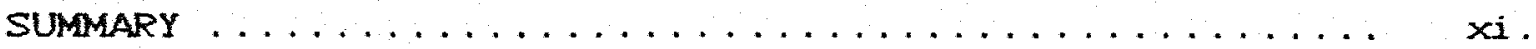

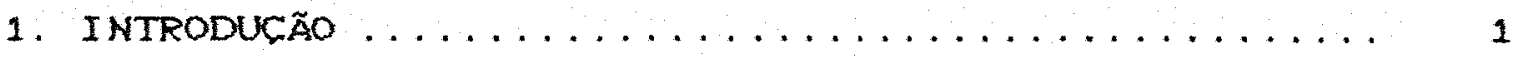

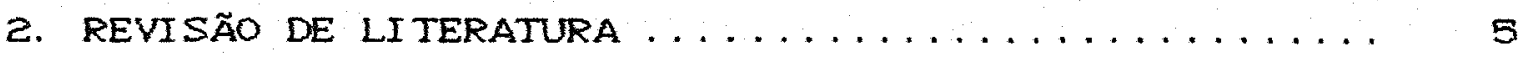

2. 1. Consideracôos Gerais ................... s

2. 2. Agentes Antibacterianos e seus Aspectos Relacionados à Saúde Humana ............... 7

2. 3. Modos de Acăo dos Agentes Antibacterianos .... 11

2. 3.1. Efeitos Metabólicos .............. 12

2. 3.2. Efeito Economizador de Nutrientes ..... 12

2. 3. 3. Efeito Contralador de Doencas ........ 13

2. 4. O Antibiótico virginiamicina ............. 14

2.5. A Virginiamicina sua Possivel Promocão de Resistência aos Antibiäticos nos Microrganis-

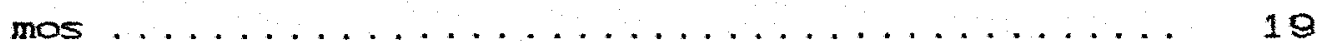

2. 6. O Uso de Virginiamicina em Aves ........... 22

2.7. O Uso de Virginiamicina em Suínos .......... 24

3. MATERI AL E MÉTODOS .................... 28

4. RESULTADOS E DISCUSSÃO ................. 32

4.1. Caracteristicas de Performance ............ 32

4. 2. Componentes Sanguíneos e Plasmáticos ....... 38 
5. CONCLUSÖES ....................... 43

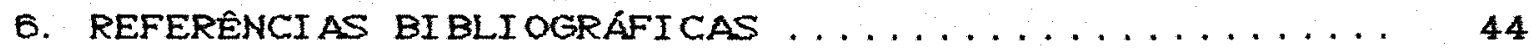
APENDICE $\ldots \ldots \ldots \ldots \ldots \ldots \ldots \ldots \ldots$ 


\section{LISTA DE FIGURAS}

Figura

Página

1 Total de Antibioticos Utilizados nos Estados Unidos da Anérica na Producão Animal, com Finalidade Medicamentosa e Não Medicamentosa no Perílodo de 1949 a 1972 CHAYS \& MUIR, 1979 ). ... 2

2 Efeitos da Virginiamicina sobre a Performance de Suínos em Recria CCA = Conversão Al imentar; $C D R=$ Consumo Díário de Racão; GDP = Ganho Diá-

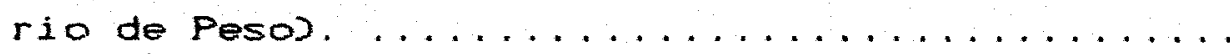

3. Efeitos da Virginiamicina sobre a Proteína Total, Globulina e Relacão Albuminarglobulina do Plasma de Suínos em Recria Alimentados com Racôes Contendo Níveis Crescentes de Virginiami-

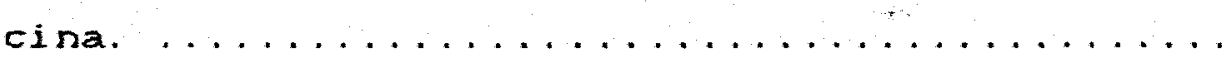


vil.

\section{LISTA DE TABELAS}

Tabela

Página

1 Composicão Química e Energia Digestivel dos Ingredientes. ....................... 29

e Composicão Percentual da Racão Basal. ........ 30

3 Médias das Caracteristicas de Performance de Suínos em Recria. Al imentados com Racão Contendo Ni veis Crescentes de Virginiamicina. ........ 33

4 Médias dos Componentes Sanguineos e Plasmáticos de Suinos em Recria, Alimentados com Racóes Contendo Niveis Crescentes de Virginiamicina. ..... 39 


\title{
A VIRGINIAMICINA COMO ESTIMULANTE DO CRESCIMENTO DE SUINOS EM RECRIA
}

\author{
Autora: JACINTA DIVA FERRUGEM GOMES \\ Orientador: PROF. DR. VALDOMIRO SHIGUERU MIYADA
}

\section{RESUMO}

o propósito deste estudo foi o de determinar o nivel dietético mais adequado do antibiótico virginiamicina como estimulante do crescimento de suínos em recria. Setenta leitões, com peso mëdio inicial $10,38 \mathrm{~kg}$, foram utilizados em um experimento em blocos casualizados, com $\theta$ repeticões, tratamento, para testar niveis de $0,25,50,75$ e 100 ppm do antibiótico na racão. Cada unidade experimental foi representada por uma baia com 2 ou 3 ani mais. A racão basal foi constituida de milho, farelo de soja, acúcar e suplementos minerais vitaminicos. A alimentacão cracôes experimentais e águal foi oferecida a vontade aos animais, durante os 28 dias de experimentacão. As pesagens individuais dos animais - a coleta de dados de consumo de racão/parcela foram semanais.

A virginiamicina proporcionou tendencias a uma resposta quadrática CP $<0,20)$ do ganho diário de peso CGDP; 
$0,469,0,495,0,523,0,516=0,508 \mathrm{~kg})$ e também quadratica $(P<0,10)$ do consumo diário de racấo CCDR; $0,90,0,97$, $0,98,0,94$ e $0,94 \mathrm{~kg}$. A conversão al imentar, por sua vez, foi linearmente $C P<0,01)$ melhorada pelo antibiótico CCA; $1,92,1,96,1,88,1,83$ e 1,85). Tais respostas puderam ser descritas, respectivamente, pelas equacôes GDP $=0,4676520+$ $0,0015645 x-0,0000116 x^{2}, R^{2}=0,96 ; \quad \operatorname{CDR}=0,904048+$ $0,002676 x-0,000025 x^{2}, R^{2}=0,77 e C A=1,93933-0,00104 x$ $R^{2}=0,59$.

No referente aos parâmetros sanguíneos e plasmáticos, o hematócrito $\mathrm{CHt} ; 31,5,32,8,32,332,3$ e $30,4 \%$. a hemoglobina $\mathrm{CHb} ; 9,92,10,38,10,17,10,10$ e $9,50 \mathrm{~g} / \mathrm{dl}$, a albumina (Alb; 2,82, 2,92, 3,00, 2,83e $2,90 \mathrm{~g}$ dl), a uréia Cur; $23,5,22,8,23,7,22,7$ e $24,7 \mathrm{mg} / \mathrm{dl}$ ) os triglicerídios (Tri; $50,3,53,3,40,7,48,8$ e 44,5 mg/dl) não for am influenciados $C P>0,05$ pelos niveis de virginiamicina na racão. Por outro lado, este antibiático determinou respostas quadráticas $C P<0,03)$ do conteúdo plasmático de globulina CGlo; 2,92, 2,80, 2,62, 2,95 e 3,08 g/dls e da relacão albumina/glabulina (Alb/Glo; $0,99,1,07,1,17,0,97$ e 0,96), além de uma tendência a uma resposta quadrática $C P<0,09$ do nível de proteina total CPt; 5,57, 5,72, 5,62, 5,78 e $5,98 \mathrm{~g} / \mathrm{dl}$. Estas respostas puderam ser descritas, respect 1 vamente, pelas equaçoes $610=2,9219050-0,0098857 x+$ $0,0001162 x^{2}, R^{2}=0,79 ; \mathrm{Alb} / \mathrm{GlO}=0,99404 \mathrm{~B}+0,004896 x-$ $0.000055 x^{2}, R^{2}=0,01$ ePt $=5.75333-0,00573 x+0,00008 x^{2}$. $R^{2}=0,02$ 
Enquanto a conversão alimentar dos leitões fôra linearmente melhorada até 100 ppm de virgíniamicina na racão, as equacóos que descrevem as respostas do ganho diário de peso e do consumo diário de racão permitiram determi nar um nivel médio de 60 ppm como o mais adequado para estas duas características. Por outro lado, as respostas da proteina total, globulina e relacão albumina/globulina do plasma permitiram estimar um nivel sensivelmente inferior, ou seja, 40 ppm. Na realidade, os resultados deste experimento evidenciam o efeito promotor do crescimento da virginiamitina em leitões en recria. 


\title{
VIRGINIAMYCIN AS A GROWTH STIMULANT \\ OF WEANLING PIGS
}

\author{
Author JACINTA DIVA FERRUGEM COMES \\ Adviser: PROF, DR. VALDOMIRO SHIGUERU MIYADA
}

SUMMARY

The purpose of this research was to determine the adequate dietary level of virginiamycin as a growth stimulant for weanling pigs. Seventy piglets with $10,38 \mathrm{~kg}$ average initial weight were utilized to test the following levels: $0,25,50,75$ and 100 ppm. A randomized complete block design, with 6 replications and 2 or 3 pigs/experimental unit (pen), was utilized. The basal diet was composed of corn, soybean meal, sucrose, and mineral and vitamin supplements. The experimental diets and water were provided "ad libitum" during the 28 day experimental periad. The pigs were weighed individually and the feed intake/pen was registered every week.

There was a tendency to a quadratic effect (P< . 20$)$ of virginiamycin on average daily gain (ADS; .469, $.495, .523, .516$ and $.508 \mathrm{~kg}$. Also, a tendency to a quadratic effect $C P<.10)$ on daily feed intake CDFI; .90, 
xii.

97. $98, .94$ and $.94 \mathrm{~kg}$ was observed. On the other hand, feed conversion (FC; $1.92,1.98,1.88,1.83$ and 1.85 ) was Iinearly $C P<.01)$ improved by added virginiamycin. All these effects could be described by the following equations: $A D G=.4676520+.0015645 x-.0000118 x^{2}, R^{2}=.96 ;$ DFI $=$ $.904048+.002878 x-.000025 x^{2}, R^{2}=.77$ and $F C=1.93933-$ $.00104 \times, R^{2}=.59$.

Hematocrit CHt; 31.5, 32. 8, 32. $3,32.3$ and $30.4 \%$, hemoglobin $\mathrm{CHb}, 9.92,10.38,10.17,10.10$ and 9.50 g $d 1)$, and plasma albumin (Alb; 2.B2, 2.92, 3.00, 2.83 and 2. $90 \mathrm{~g} / \mathrm{dl}$ ), urea $(\mathrm{Ur} ; 23.5,22.8,23.7,22.7$ and $24.7 \mathrm{mg} / \mathrm{dl})$ and triglycerides CTri; $50.3,53.3,40.7,48.8$ and 44.5 mgrdl) were not affected $(P) .05)$ by the virginiamycin levels of the diet. However, this antibiotic determined quadratic responses $(P<.03)$ of plasma globulin CGIo; 2.92 , 2. $80,2.62,2.95$ and $3.08 g / d l$ and albumin/globulin ratio CAlb/Glo; $.99,1.07, .97$ and $.96 . \mathrm{Also}$ a tendency to a quadratic response $C P<.09$ of plasma total protein level (Pt; 5.57, 5.72, 5.62, 5.78 and $5.98 \mathrm{~g} / \mathrm{dl}$ ) was observed. These responses could be described by the following equations: $610=2.9219050-.0098857 x+.0001162 x^{2}$, $R^{2}=.79 ; A 1 B / G 10=.994048+.004896 x-.000055 x^{2}, R^{2}=.61$ and $P t=5.75333-.00573 x+.00008 x^{2}, R^{2}=.92$.

The mathematical equations of $A D G$ and DFI allowed to determine 60 ppm of virginiamycin as the best dietary level for weanling pigs, even though the FC was linearly improved up to $100 \mathrm{ppm}$. On the other hand, plasma 
xiil.

total protein, globulin and albuminiglobulin ratio showed that the dietary virginiamycin level could be lower 640 ppm. Therefore, the results of this experiment showed that virginiamycin can be an efficient growth promoter for weanling pigs. 


\section{INTRODUÇ.̃̃O}

Uma análise da evolucão histórica a respeito da utilizacâo de agentes antibacterianos, como aditivos de ração, mostra que estes produtos vem sendo largamente utilizados na producão animal (VISEK, 1978), resultando em uma eficiente producăo de ali mentos de origem animal.

Nas últimas três décadas, isto é, décadas de 60,70 e 80 , as aditivos antibacterianos desempenharam um importante papel no crescimento e desenvol vimento da indústria suína, através do aumento da taxa de ganho de peso da eficiência alimentar dos animais (HARPER \& KORNEGAY, 1983$).$

Nos Estados Unidos da América, os antibióticos têm sido utilizados extensivamente na producão animal desde a sua introducão na década de 50. A Figura 1 mostra um crescimento no uso de antibióticos naquele país a partir da década de 50. Paralelamente, houve também un aumento no uso dos antibióticos com finalidade não medicamentosa. Assim, para o final da década de 60 fol estimada a utilizacão de mais de 1 milhão de quilogramas de antibióticos anual mente, com funcão não medicamentosa em racões ani mais CHAYS \& MUIR, $1979)$. 
2.

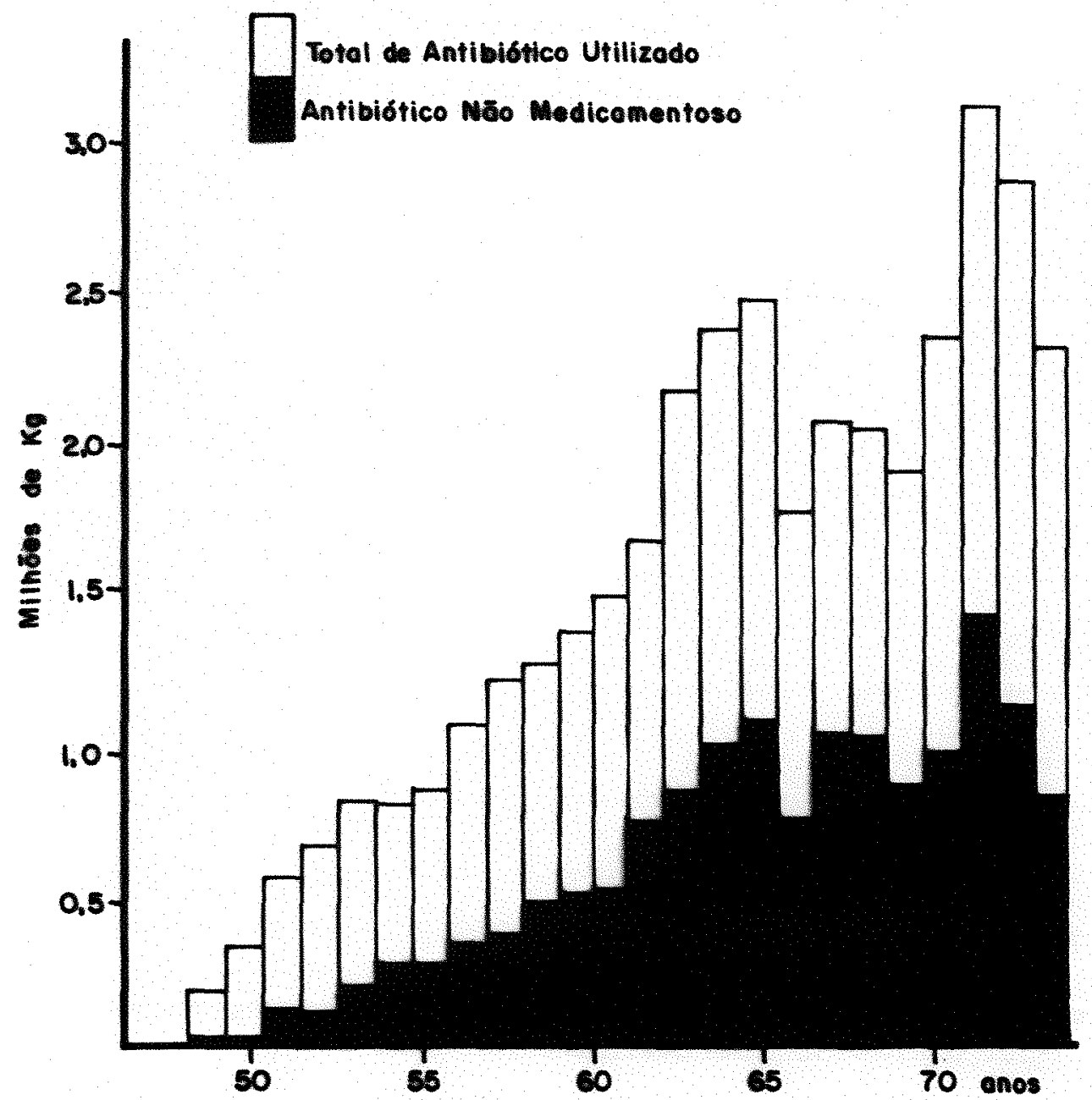

Figura 1 - Total de Antibioticos Utilizados nos Estados Unidos da América na Producão Animal, com Finalidades Medicamentosa e Não Medicamentasa no Período de 1949 a 1972 (HAYS \& MUIR, 1979 ). 
De maneira geral, na literatura há fortes evidências dos efeitos favoráveis dos antibióticos na producão de suínos. Tals efeitos envol vem melhorias no ganho de peso, na conversão al imentar e também uma importante di mi nuição na mortalidade e morbilidade de leitões provocadas por microrganismos patogênicos (CUNHA, 1977 e HAYS \& MUIR, 1979 .

O modo de acão dos antibióticos, como promotores de crescimento de suínos, ainda não é completamente entendido. No entanto, diversos mecanismos têm sido sugeridos CWALACE, 1970; UISEK, 1978; MAYNARD et alii, 1979; ENSMINGER \& OLINTINE, 1980 e RIBEIRO et ali $i, 19843:$ os antibióticos reduzem a destruicão microbiana de nutrientes essenciais no trato gastrointestinal, aumentam a sintese de vitaminas, inibem o crescimento de organismos produtores de toxinas diminuem a espessura da parede do trato intestinal, resultando em aumento da eficiencia de absorcão e utilizacăo de nutrientes.

Na realidade, o efeito benéfico dos agentes antibacterianos na performance dos suínos depende de diversos fatores, tais como condicōes ambientais, manejo, idade erou peso do animal, período de fornecimento da droga, condicões sanitárias das instalacóes, concentracão do produto na racão, composicão da racão, etc... CWALACE, 1970 ; VISEK, 1978; BRAUDE, $1978 \mathrm{ab}$; HAYS \& MUIR, 1979 \&ELLAVER et a $i i$, 1982). Por exemplo, sabe-se que quanto melhor a condicão sanitária e nutricional do rebanho, menor é a resposta aos agentes antimicrobianos. 
Dentre os diversos agentes antibacterianos, a virginiamicina se destaca como um antibiotico utilizado na promocão de crescimento e melhoria da eficiencia alimentar de perus, frangos de corte, bezerros e suínos cCuOLLO, 1979). Ela não é utilizada como um produto terapêtico em saúde animal ou humana (SMI THKLINE, 1977 ).

Assim, este estudo teve como objetivo determinar o nivel dietético mais adequado de virginiamicina como estimulante do crescimento de suinos em recria, através dos dados de performance e dos componentes sanguíneos e plasmáticos dos animais. 


\section{REVISĂO DE LITERATURA}

\subsection{Consideracões Gerais}

No Brasil, a utilização de antibióticos na alimentacão animal, como estimulantes do crescimento, vem ocorrendo desde o inicio dos anos 50 (ALESSANDNO, 1962$).$

A realizacão de experimentos com suinos $\theta$ aves, principalmente nas décadas de 50 e 80 , permitiu o desenvolvimento de importantes conhecimentos sobre aditivos promatores de crescimento (WALLACE, 1970$).$

- fato de a média de aumento na taxa de crescimento ter permanecido relativamente constante, desde o inicio da utilizacão dos antibibticos na alimentacão ani mal, sugere a não ocorrência de fatores causadores de resistência a antibióticos ou sua transferéncia entre os microrganismos CVISEX, 1978; MENTEN, 1988 .

Foi no ano de 1975, que a Food and Drug Admi nistration (FDA) aprovou $O$ uso de um grande número de antibiaticos e combinaçôes destas drogas nas indústrias de racões para a promocão do crescimento animal. Entretanto foi detectado neste mesmo periodo, um declínio no uso de antibióticos devido, principalmente, ao considerável aumento 
b.

no uso de promotores de crescimento não antibióticos, particularmente o cobre para suínos (BRAUDE, $1978 a$ ).

En 1978, eram conhecidos cerca de 4.000 antibióticos e 3.000 qui mi oterápicos (BRAUDE, 1978b), sendo que destes, 20 são utilizados como promotores do crescimento em uma ou mais espécie animal. Este é o caso da virginiamicina, bacitracina de zinco flavomicina, que são classificados produtos de uso não terapêutico, enquanto que penicilina, tetraciclina, sulfonamida, estreptomicina e neomicina são de uso terapeutico. Esta divisão de categoria, segundo VISEK (1978), está baseada na acor réncia de desenvol vi mento de resistencia nas bactérias entéricas dos animais como resposta ao uso das drogas. Este desenvolvimento de resistência das bactérias às drogas dificultaria, ou até mesmo, invalidaria - tratamento de doencas nas espécies ani mal e humana.

Os antibióticos são substâncias produzidas por organismos (fungos e bactérias) em fase ativa de crescimento (CAON, 1955$)$ que possuem propriedades bacteriostatica ou bactericida (ENSMINGER \& OLINTINE, 1980), ou seja, que possuem a capacidade de, respectivamente, inibir o crescimento - destruir os microrganismos CCAON, 1955; WALLACE, 1970 CUNHA, 1977). Muitos deles já trouxeram valiosas contribuicôes na luta contra os microrganismos patogênicos CCAON, 1955 .

Aqueles antibióticos que não são absorvidos pelo intestino são de menor importância na terapia humana, mas podem ser amplamente utilizados para a promocão do cres- 
cimento controle de doencas entéricas nos animais.

Para que a utilizacão dos antibióticos na produção animal promova um máxi mo efeito benéfico, é necessário que esta utilizacão seja feita de maneira racional, dentro de programas bem elaborados que não visem a substituicão, por exemplo, de práticas sanitárias e nutricionais pela simples resposta benéfica trazida pelos antibióticos CHOUWELING \&. GAINER, 1978 .

\subsection{Agentes Antibacterianos e seus Aspectos Relacionados à Saúde Humana}

No decorrer da década de 60, estudos "in vitro" mostraram a possibilidade do desenvol vimento de resistência transferida entre bactérias entëricas, isoladas do animais alimentados com racóes contendo baixos contínuos níveis de antibióticos (LANGLOIS et ali 1 , 1978). Ial fato foi responsável pela formação de comitês na Inglaterra e Estados Unidos da América, a fim de estipular recomendacóes sobre o uso de antibióticos na alimentarão animal. O comitê formado na Inglaterra recomendou que os antibióticos de aplicação terapêtica em humanos ou animais, que pudessem promover resistencia cruzada, não poderiam ser utilizados como aditivos para a promocão de crescimento. Esta recomendacão foi implantada em 1971 pelo governo ingles.

o comitê da Food and Drug Administration CFDA, reunido em 1972, encontrou também, como principal restricão 
ao uso de antibióticos, a resistência dos microrganismos devido ao seu uso subterapêtico. Segundo HAYS \& MUIR (1979), os residuos em tecidos a resistência microbiana são as principais preocupacóes com a seguranca da saúde pública quando se utiliza de drogas antibacterianas; sendo as causadoras de maiores atencóes as sulfas, com relacão a residuos em tecidos, e a tetraciclina e penicilina com rela\&ão a resistência microbiana.

Agentes utilizados na alimentacão animal não estão sujeitos a prescricão veterinăria e incluem a bacitracina, a flavomicina e a virginiamicina. As drogas terapêticas, como a penicilina e as tetraciclinas, necessitam de prescricão veterinária para sua utilizacão na producão animal (LANGLOIS, 1978 e SOLOMONS, 1978 ).

Segundo HOUWELING \& GAINER ( 1978 ), todas estas preocupacões em relacão aos agentes antimicrobianos são devido a fatores como:

a) o uso de antibióticos favorece a selecão e o desenvolvimento de resistência simples ou múltipla nos microrganismos;

b) animais que recebem quantidades subterapeuticas e/ou terapeuticas de antibióticos na racão podem servir como portadores de patágenos e não patágenos resistentes a antibióticos, sendo os portadores de patógenos possiveis causadores de infeccões nos seres humanos: 
9.

c) a prevalência de bactérias patogênicas e năo patogênicas multiresistentes, portadoras do "fator R" Cfator de resistêncial tem aumentado tem sido responsabilizada ao uso de antibióticos;

d) organismos resistentes a agentes antibacterianos têm sido encontrados na carne ou derivados da carne; e

e) há aumento na ocorrencia de bactérias resistentes a antibióticos no homem.

De acordo com HOUWLING \& GAINER (1978), são dois os parâmetros utilizados para estabelecer um possível risco à saúde humana, devido ao uso de agentes antimicrobianos na producão animal: o fator bacteriológico e epidemiológico, o fator farmacológico.

- primeiro fator sugere um risco à saúde humana, caso o uso de um agente antibacteriano na alimentacão animal:

a) resulte em um significativo aumento do organismo Salmonella, a qual pode ser transmitido através da cadeia alimentar do homem podendo provocar doencas. Entretanto, SOLOMONS (1978) não observou nentum efeito prejudicial da utilização de antibiático, a nível subterapêtico, sobre a ocorrencia deste organismo na carne animal; 
b) promova significant aumento nos organismos gram-negativos, principalmente Escherichia coli, resistente aos agentes antibacterianos usados sistematicamente na medicina clínica humana. Entretanto, nenhuma evidencia fol registrada em estudos realizados por SOLOMONS (1978) sobre o perigo ao homem em relacão a $E$. coli de origem animal, atraves do uso de antibióticos em niveis subterapêticos:

c) aumente a patogenecidade de organismos gram-negativos nos animais pelo aumento da producão de toxinas com "fator R":

d) aumente, no ser humano, a flora de bactérias patogênicas resistentes a agentes antibacterianos usados no tratamento de doencas dos seres humanos causados pela ingestão de residuos biologicamente ativos nos alimentos.

Já o fator farmacológico indica que a existência de agentes antibacterianos nos alimentos, em quantidades capazes de induzir alergia ou hipersensibilidade, representa um grande risco à saúde humana.

Portanto, a recomendacão é que o uso de penicilina e tetraciclinas na alimentacão animal não deve acorrer, sendo os mesmos apenas de uso terapêtico. 
Al gumas informaçbes mostram que foi detectado um aumento significativo de resistência em algumas culturas bacterianas desde a introducão dos antibióticos como aditivos de racôes. Entretanto, a resposta de crescimento independe do mecanismo responsável pela aquisicão de resisténcia ou de sua transforoncia entre cepas ou espécies de microrganismos (VISEK, 1978 ).

Segundo afirmacões de SOLOMONS (1978), nenhum dos estudos realizados apresenta evidencias de que o uso de níveis subterapêuticos de antibióticos em racôes comprometa - tratamento subsequente de doencas clinicas nos animais.

\section{3. Modos de Acăo dos Agentes Antibacterianos.}

É absolutamente necessário estabelecer os efeitos modos de acão de um antibiótico sob condicôes experimentais, a fim de se obter resultados confiáveis. Contudo, os efeitos resultantes da experimentacão podem ser menores quando realizados em laboratórios do que em estudos de campo, devido as melhores condicões ambientais sanitárias oferecidas por ambientes experimentais (KUTHER, 1981 ).

E bastante conhecida a capacidade dos agentes antibacterianos em aumentar a eficiencia de utilizacão dos alimentos ou causar economi a de nutrientes essenciais sob uma variedade de condicões (VISEK, 1978). Entretanto, ainda são inúmeras as propostas sobre os diversos modos de acão destes agentes, sendo três as principais propostas: 
- ereitos metabólicos;

- efeito economizador de nutrientes e;

- efeito controlador de doencas.

\title{
2.3.1. Efeitos Metabólicos
}

\begin{abstract}
Ainda não está bem definida a questão do efeito metabólido causado pelos aditivos em relacão ao sistema enzi mático do animal hospedeiro ou da sua microflora, entretanto segundo WALLACE (1970), estes efeitos podem ocorrer devido às propriedades bacteriológicas dos antibióticos e outros aditivos.
\end{abstract}

\section{3.2. Efeito Economizador de Nutrientes}

Os microrganismos ruminais ou intestinais sintetizam certos aminoácidos e vitaminas, e devido a isto competem com o hospedeiro pelos nutrientes disponíveis. Assim, no caso de nutricão deficiente ou li mitada, o aditi vo mel hora o desempenho animal através da estimulacão da sintese microbiana do nutriente crítico ou através da supressão dos organismos competidores com o hospedeiro por certos nutrientes (WALLACE, 1970 . 


\subsubsection{Efeito Controlador de Doencas}

A acăo dos antibióticos ocorre principalmente devido às propriedades preventivas e terapêticas de certas afeccóes que alteram o estado de saúde dos animaís, 1 imi tando sua capacidade de utilizacão dos al i mentos e consequentemente de producão.

Os agentes antibacterianos promotores de crescimento modificam a microflora ou seus produtos no interior do trato gastrointestinal, sendo que não é observado al teracóes quantitativas na populacão de espécies microbianas intestinais (VISEK, 1978 ).

No intestino, os agentes antibacterianos promotores de crescimento atuam mais eficientemente quando a flora microbiana não se encontra total mente equilibrada. quando ainda está em situacão competitiva, como é o caso da fase pós-desmama fase inicial de crescimento. Com o avancar da idade, ou seja, durante a fase de crescimento-terminacão, o suino possui uma flora intestinal em situacão de cooperacão, onde as populacóes de micror ganismos já estão estabilizadas. Devido a este fato, tais agentes são mais eficientes em promover mel horias no consumo de racão o na taxa de crescimento em suínos jovens de ate 4 a 6 semanas de idade CCLAYSON \& ALSMEYER, 1973 e MOSER et ali $i, 1985$.

Desde o início dos estudos sobre a utilizacão de antibióticos, foi aceito que a resposta de crescimento a estes agentes é devido à sua acão sobre a flora microbiana 
(VISEK, 1978 - MENTEN, 1988). Entre as pesquisas que evidenciam tal afirmativa. estão aquelas que mostram a falta de melhorias no crescimento de animais sob condicões 1 ivres de patógenos específicos (minimal disease). Outra evidencia, suportando a acão antibacteriana, é a de que os agentes antibacterianos sâo mais eficientes promotores de crescimento em ambientes de higiene precắria do que em ambientes isolados ou em populacbes de animais muito bem manejados (WALLACE, 1970 V VISEK, 1978$).$

Além das bactérias causadoras de doencas subclinicas, existem aquelas causadoras de distúrbios, através da producão de amônia, que altera histologicamente o epi télio respiratório, entre outros, aumentando demasiadamente a incidência de infeccôes por vírus e micoplasma (VISEK, 1978 .

\section{4. Antibiótico Virginiamicina}

Os produtos que têm a virginiamicina como principio ativo vêm sendo utilizados em raçôes animais em diversos paises dos cinco continentes, incluindo o Canadá, Franca, Bélgica, Holanda, Itália, Inglaterra, Portugal, Espanha, México, Argentina, Brasil e também as Estados Unidos da América, onde este antibiótico foi aprovado como aditivo de racão suína somente em 1975.

Em países como a Franca, Alemanha e a Suíca, a virginiamicina utilizada no tratamento de infeccóes causadas por estafilococus. Nos demais países este uso terapêti- 
co proibido (CRAMFORD, 1984 ).

A virginiamicina um antibiotico que se apresenta como um pó branco, amorfo de reacão neutra CTHE MERK INDEX, 1978), dissolvendo-se em $p H$ alcalino, ao redor de 9.5, com rápida inativasão. É completamente sol úvel em metanol, etanol, acetona, clorofórmio benzeno, e insolúvel em água CVERVAEKE et alii, 19792.

A primeira vez que se isolou tal antibiótico fai no início da década de 60, em solos belgas CMILES, 1981 ; CRAWFORD, 19842.

As propriedades biológica e química da virginiamicina assemelham-se a de compostos como micamicina, ostreogricina, fator $P_{114}$, pristinamicina, estreptogramina e vernamicina. Todos estes antibiaticos possuem dois fatores de atividade sinérgica contra um grande número de microrganismos, o fator $M$ o fator S CTHE MERK INDEX, 1970; SMITH KLINE, 1977; ABOU-YOUSSEF et ali $i, 1979$ CRAYFORD, 19843. O primeiro fator, presente em maior concentracão, consiste em uma lactona macrociclica contendo um anel oxalona, com formula molecular $\mathrm{C}_{28} \mathrm{H}_{35} \mathrm{~N}_{3} \mathrm{O}_{7}$ e estrutural:

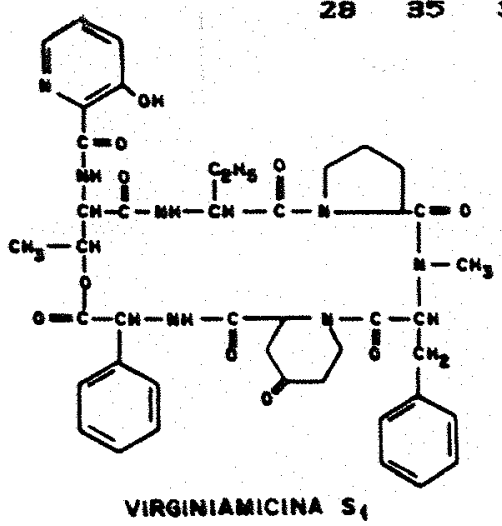


16.

o fator S, o menor componente, consiste de um anel lactona ciclopeptídico, de fórmula molecular $\mathrm{C}_{4} \mathrm{H}_{40} \mathrm{~N}_{7}$ $0_{10}$ estrutural:

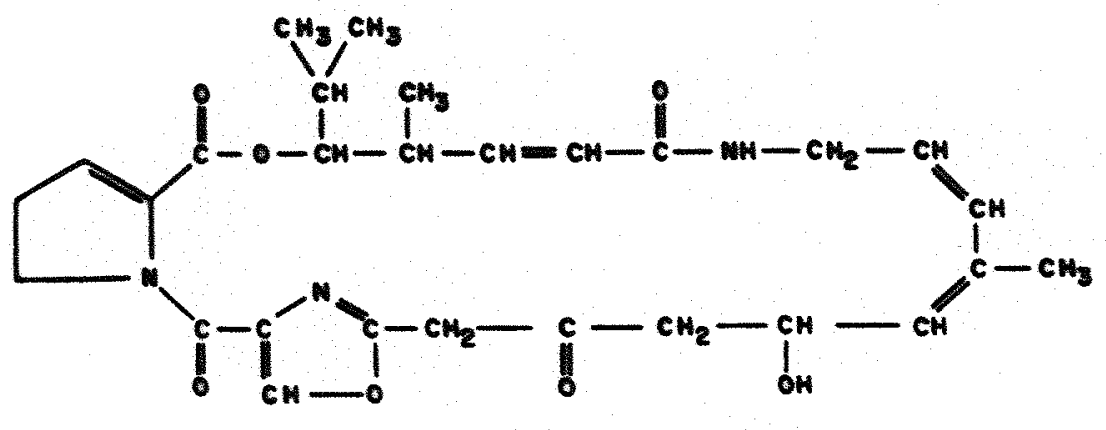

VIRGINIAMICINA M,

Estes dois fatores, quando encontram-se separados, exercem atividade bacteriostática reversivel sobre a suscetibilidade bacteriana, incluindo o Bacillus subtilis, e em combinacão, são de ação bactericida (CRAWFORD, 1984$).$

- organismo responsável pela producão da virginiamicina é a bactéria mutante streptomyces virginiae, que possui primeiramente atividade contra organismos gram-positivos CHARPER et alii, 1983b; PELURA et alii, 1980; CRAYFORD, 1984 e PACHECO, 1988), atuando contra organismos como Hemophilus e Neiseria spp. possuindo também atividade contra Toxoplasma gandi. Plasmodium berghei e Treponema hyodysenterial, o presumivel agente causador da disenteria suína. 
Segundo estudos realizados por COCITO (1989). - modo de acão da virginiamicina se dá através da inibicão da sintese protéica microbiana, especificamente pela inibicão da formacão peptídica a nível de traducão, pois imediatamente a exposicão dos microrganismos à virginiamicina. ocorre alteracão do RNA ribossômico CrRNA), o qual fica inibido. A metilação do rRNA diminuida na presenca do antibiótico, sendo que as células tratadas passam a ter o rRNA instável metabolicamente.

A sintese de proteina envol ve a formacão da cadeia peptidica por um complexo consistindo no RNA ribossómico e mensageiro pelo processo conhecido como traducão (SMI THKLINE, 1977), o qual é inibido pela acão da virginiamicina. Embora o processo não seja ainda completamente entendido, há uma teoria de que a virginiamicina liga-se irreversivelmente a um sitio receptor sobre a subunidade ribossômica. Assim, esta ligacăo irreversivel da virginiamicina refere-se provavelmente à natureza bactericida de sua ati vidade.

Os antibióticos como a virginiamicina elevam o pH do conteúdo intestinal dos animais, proporcionando átimo pH as enzimas pancreáticas intestinais, em um valor mais elevado do que o normalmente encontrado, o que resulta em aumento da digestão dos carboidratos, proteínas e lipideos CSMI THKLINE, 19773.

A virginiamicina é responsável pela modificacão da composicão e distribuicão da flora intestinal favore- 
cendo a flora bacteriana do tipo cooperativo e inibindo a do tipo competiti vo (SMI THKLINE, 1977 ).

Outro modo de ação ocorre através da diminuicão da fermentacão da glucose propiciando reducão de producão microbiana de ácido láctico e ácido graxos voláteis CAGV CVISEK, 1978; ABOU-YOUSSEF et ai $i, 1979$; VERVAEKE et ali 1 1979). A inibicão da fermentacão da glicose promove uma economia de $2,68 \%$ da energia líquida, a qual poderá ser utilizada como energia de crescimento. Baseados nestes dados obtidos "in vivo" e "in vitro", VERVAEKE et alii (1979) concluíram que a promocão de crescimento causada pela virginiamicina é devido a uma importante mudanca no metabolismo energético bacteriano de carboidrato. Assim, em termos de mudancas na flora intestiral são muito mais importantes mudancas no metabolismo bacteriano do que mudancas no número das populacôes bacterianas. Há então uma diminuicão da producão de metabólitos finais não assimiláveis, o que faz com que os nutrientes passem a ser utilizados no crescimento - producão de carne CVERVAEKE et alii, 1979s. o tempo de contacto dos alimentos com a parede intestinal é prolongado por uma possivel diminuicão do peristaltismo intestinal, o que promove uma maior absorcão de nutrientes, já que a mesma, pelo uso do antibiótico. não se encọtra irritada por uma excessiva fermentação bacteriana. RAVINDRAN et ali $i$ (1984) também confirmam tais afirmacões, entretanto complementam dizendo que somente ocorre aumento na absorcão e retencão de nutrientes, em suínos alimentados com dietas de 
elevado conteúdo fibroso em comparacão a dietas convencionais, ambas em presenca de virginiamiclna.

Estudo realizado por CRAYFORD (1984) enfoca a questão farmacotécnica em relação ao uso do antibiótico citado. Este pesquisador afirma que a virginiamicina desaparece rapidamente da corrente plasmática a uma taxa exponencial sendo sua mei a vida de aproxi madamente cinco horas. Observa- se que a bile representa a principal rota de excrecão corporal, entretanto a eliminacão se dá, também, através das fezes. Sob condicões ambientais a virginiamicina é rapidamente degradada com $87 \%$ da perda de sua atividade após sete dias, sendo que após vinte um dias não se detecta nenhuma atividade.

\subsection{A Virginiamicina e sua Possivel Promocão de Resis- tência aos Antibióticos nos Microrganismos}

A virginiamicina é um composto que se apresenta sob a forma granular e que resiste a altas temperatura e pressão. Isto é muito importante, uma vez que a racão inicial, na qual é adicionado este antibiótico, passa por elevadas temperatura e pressão durante o processo de peletizacão. Foi observado também que não há interacão da virginiamicina com qualquer outro ingrediente de racão, e nem há acão sinérgica deste com outros antibióticos CCRAWFORD, 19842. 
20.

Embora a virgini amicina não possua ação contra microrganismos gram-negativos, o que não estimula o desenvolvimento de resistência nas bactérias mais conhecidas na transmissão do fator $R$ de resistencia, é um erro negar a possibilidade de aquisicão de resistencia bacteriana quando do uso de antibiaticos, pois, segundo CRAFFORD (1984), suínos alimentados com racões contendo clortetraciclina, oxitetraciclina, oleandomicina espiramicina, apresentaram aumento de cepas bacterianas resistentes.

De acordo com WALLACE (1970), o prolongado período de utilizacão dos agentes antibacterianos, como os antibióticos, possivelmente não é o responsável pelo surgimento de cepas de organismos resistentes. Isto é confirmado por resultados de estudos "in vitro" e "in vivo" que mostram que a resistência à virginiamicina desenvolvida pelos microrganismo ocorre muito lentamente (SMI THKLINE, 1977 ).

Quando se compara a clortetraciclina, virginiamicina e tilosina em termos de promoçăo de resistencia. observa-se, através das respostas obtidas por HOWELING \& GAINER (1978), que a clortetraciclina é a causadora de maior resistência, em relação às demais.

De acordo com os resultados obtidos em estudo realizado por LANGLOIS et alii (1978), as racóes suplementadas com antibióticos foram responsáveis por um aumento nas bactérias entéricas gram-negativas nos animais. A virginiamicina que é eficaz contra certas bactérias gram-positivas, tem sido reportada como a causadora de uma significativa mu- 
danca na flora gastrointestinal de leitóes, pelo decréscimo do número de lactobacilus enterococus cMey et ali $i^{1}$, eitado por LANGLOIS et alii, 1978). Os lactobacilus e enterococus tenderam a decrescer enquanto que a populacão de coliformes aumentou nas amostras fecais de suinos alimentados com a virginiamicina. Entretanto, a populacão dos três grupos de bactérias retornaram ao seu nível original uma semana após a retirada da virginiamicina da dieta.

Extensas revisóes, realizadas por cuollo (1979), MILES (1981) MLLER et alii (1981) revelam que a virginiamicina é um antibiótico que, primeiramente, exibe atividade contra microrganismos gram-positivos apresentando baixo nivel de atividade contra os gram-negativos o que assegura a este antibiótico pouca probabilidade de desenvolvimento de resistência nos microrganismos (SMITHKLINE, 1977 ). Não ocorre também nenhuma ati vidade contra fungos e leveduras. Este fato elimina qualquer impacto que o antibiótico possa vir a causar sobre as principais classes de microrganismos do solo, quando se pensa nos efeitos dos dejetos suinos em relação ao meio ambiente, pois o mesmo é rapidamente degradado sob condicões ambientais, não alterando a microflora do solo ou das lavouras cultivadas neste solo. Não existe também, por parte da virginiamicina, nenhum tipo de contaminacão dos ecossistemas aquáticos.

\footnotetext{
4MEY, L.E. de; Assche, P.F.; DEschures, J. Effect in vitro" of growth promoting antibiotics on the composition and biochemical activity of the gastraintestinal flora in piglets. Nutr. Abstr. and rev. 46 : 154, 1070 .
} 
22.

ABOU-YOUSSEF et ali $i$ (1979) avaliaram o efeito de niveis subterapêticos de virginiamicina sobre a ocorrência e duracão de infeccão causada por Salmonel la typhemurium em suínos. Estes pesquisadores não observaram mudancas significativas no processo infeccioso dos animais infectadose tratados durante 2 meses com 50 ppm de virginiamicina em relacão aos animais do grupo controle. Tal resposta confirma que o uso da virginiamicina, como aditivo de racôes de suínos, não resulta em mudancas significativas no decorrer da infeccão, o que mostra que este antibiótico não atua como supressor de doencas e sim como promotor de crescimento. Pode, então, ser possivel o desenvol vimento de resistencia bacteriana em funcão do antibiótico utilizado.

- FDA evidencia que não é necessắrio o períado de carência da virginiamicina quando esta é componente de racão de suínos em fase de terminacão.

\subsection{Uso de Virginiamicina en Aves}

Nos Estados Unidos da América, o uso do antibiótico virginiamicina já é bastante difundido como promotor de crescimento de aves, como frangos e perus.

A empresa produtora do antibiótico virginiamicina recomenda níveis de 5 a 20 ppm deste antibiótico como promotor de crescimento, dependendo das condicões de manejo - idade das aves. 
23.

COMBS \& BOSSARD (1983) trabal haram com aves alojadas em galpões contendo camas novas não contaminadas e camas contaminadas. Foi utilizado o nivel de 8 ppm de virginiamicina, sendo este mesmo nível responsável por uma resposta positiva significativa na performance das aves alojadas sobre camas contaminadas, observado através de melhoria do ganho de peso das mesmas en cerca de 4,9\%. As aves alojadas sobre camas novas, não apresentaram nenhuma resposta ao antibiótico, confirmando teoria defendida por diversos pesquisadores CEYSSEN \& SOMER, 1967; WALLACE, 1970; VISEK, 1978 - BELLAVER et ali i, 1982 de que as respostas aos antibióticos são inversamente proporcionais ao estado sanitário das inst.al acôes.

Os dados de literatura variam em relacâo à concentracão ideal de virginiamicina que deve ser utilizada para a obtencão de melhores dados de performance das aves. Os pesquisadores EYSSEN \& SOMER (1967) indicaram que um nivel dietético de 20 ppm de virginiamicina promoveu uma melhora significativa no desempenho de aves que apresentavam problemas de decréscimo de eficiência alimentar causada por uma má absorcão de gorduras e carboidratos da dieta. Em outro experimento, estes mesmos pesquisadores detectaram a necessidade do uma dosagem acima de 20 ppm de virginiamicina para reestabelecer o desenvol vimento de aves SPF, que haviam sido inoculadas com microrganismos comuns ao trato gastrointestinal. 
Os diversos relatos CSMI THKLINE, 1977; MILES, 1981; ADAMS \& LARSON, 1980 COOK \& ORT, 1988) são unâni mes quanto à eficiencia da virginiamicina como melhoradora da conversão al imentar e ganho de peso das aves. ADAMS \& LARSON (1986) observaram mel horias de $1,48 \%$ de $3,09 \%$, respectivamente, no peso e na conversão alimentar, quando da utilizacão de 10 ppm de virginiamicina em dietas de aves. Já CoOK \& ORT (1988) encontraram, utilizando esta mesma concentracão, aumentos da ordem de 0,2 a $3,2 \%$ no peso corporal e melhora de 0,6 a $7,0 \%$ na eficiência alimentar das aves.

Em relacão a producão média de ovos, esta foi significativamente mai or em poedeiras alimentadas com níveis de virginiamicina de 10 e 20 ppm, segundo as pesquisas realizadas por MILS (1981), o qual obser vou também que a maior producão de ovos foi acompanhada por um menor peso dos mesmos. Não foi dada explicacão para este fato, mas é sabido que o aumento na producão de ovos irá compensar a diminuicão no seu tamanho. Uma vantagem trazida pela diminui ã̃o do tamanho dos ovos a reducão do problema da qualidade das suas cascas, diversas vezes observado em galinhas em fase final de producão que ovopositam ovos de maior tamanho CMILES. 19813.

\subsection{Uso de Virginiamicina em Suinos}

A grande maioria dos trabalhos de pesquisa realizados com a virginiamicina como promotor de crescimen- 
25.

to, provém dos Estados Unidos da América. Estes resultados envolveram as diversas fases do ciclo de producão animal: recria e/ou crescimento e/ou terminacão. Embora nestes trabalhos tenham sido testados distintos niveis do antibibtico, como por exemplo 11, 20,50 e $88 \mathrm{ppm}$, ficou demonstrado que a virginiamicina pode promover melhoria da conversão alimentar CHAYS et alii, 1973; KRIDER et ali alii, 1970; PELURA et alii, 1980; MLLER et alii, 1972 e WHI TE $t$ ali $i, 1988$, assim como do ganho diário de peso dos animais CJONES \& POND, 1963; HAYS et ali $i, 1973$; KRIDER et alii, 1975 e MLLER et alii, 1972s. As pesquisas realizadas com suinos em recria mostram que a suplementacão de racóes com a virginiamicina promove pouco efeito sobre os microrganismos entéricos.

Embora di versos pesquisadores tenham observado efeitos positivos no desempenho animal, promovido pela virginiamicina, outros CKRIDER et ali, 1975; HARPER et ali $i$, 1983; RIBEIRO et ali 1984 e HOPPE et ali 1,1988 ) obtiveram apenas uma tendência à melhora da conversão alimentar e aumento no consumo diărio de racão dos ani mais experi mentais.

Em relacão à populacão de microrganismos, os coliformes, lactobacilus e estreptococus são os mais importantes no estómago e intestino del gado dos suínos. o número de lactobacilus e estreptococus CHAYS et alii, 1973 . VERVAEKE et ali $i, 1979$ diminui marcadamente o de coliforme não é influenciado (VERVAEKE et ali i, 1979), quando a virginiamicina é oferecida na racão de suinos em crescimen- 
26.

to. Este decréscimo no número de lactobacilus e estreptococus corresponde a um decréscimo na produção de ácido lático.

A combinacão da virginiamicina com o cobre tem proporcionado respostas positivas significativas aos parametros de ganho diário de peso e consumo diário de racão CBAREER et ali $i, 1978$ e STAHLY ot ali $i, 1980$, assim como da conversão ali mentar (JONES \& EASTER, 1986), não alterando entretanto, nenhuma das características de carcaca CRELLAVER et alii, 19823 .

A suplementacão com virginiamicina retarda significativamente a taxa de passagem do conteúdo intestinal, tanto em dietas baixas quanto altas em fibra; entretanto, só melhora a digestibilidade da matéria seca, energia, fibra detergente neutro, fibra detergente ácido, hemicelulose e celulose em dietas altas em fibra CRAVINDRAN et ali $i$, 1984). Isto demonstra que a virginiamicina é responsável por sensivel melhora na digestibilidade de dietas fibrosas, pois este antibiótico prolonga a retencão da digesta no intestino grosso, expondo a mesma a digestão microbiana por período de tempo maior. Assim, os produtos da degradacão de fibras passam a ser utilizados como energia pelos suinos. Entretanto, outros trabalhos mostram que a virginiamicina diminui significativamente a digestibilidade de dietas fibrosas CCLEMMER \& SEERLEY, 1984), ou não influencia na utilizacão de fibras pelos suínos (HOPPE et alii, 1988). As divergências dos resultados podem ser devido a uma série de fatores, tais como, a idade do animal, balanco nutricional da dieta, 
estádio de maturacão da planta ribrosa, etc...

Um fator extremamente importante que al tera a performance dos suínos a lotacão das baias. A al ta lotacão pode reduzir a resistência geral dos suínos, tornando-os mais suceptiveis a certos microrganismos comuns ao meio ambiente (HARPER \& KORNEGAY, 1983 ), ou então a desequilibrios na flora intestinal comuns no período de desmama. Assim, um antibiótico como a virginiamicina pode reduzir CHARPER \& KORNEGAY, 1983 MOSER et alii, 1985 o risco do efeito negativo do estresse da desmama. Segundo HARPER \& KORNEGAY (1983), a ausência de resposta significativa à virginiamicina, em situacão de alta lotacão, pode ser devido ao fato da restricão de espaco não ter sido suficientemente severa para reduzir a resistência dos suínos e/ou o nivel de microrganismo não ter sido suficientemente elevado a fim de provocar destúrbios. O NATIONAL RESEARCH COUNCIL (1984) relatou a existência de interacão entre antibiótico x espaco. Assim, as maiores respostas à virginiamicina geralmente são obtidas com suínos alojados em baias de maior lotacão. Entretanto, MOSER et alii (1985) não observaram nenhuma interacão entre estes fatores, sugerindo que, independentemente da lotacão, os suínos respondem de forma similar à suplementacão com a virginiamicina. 
28.

\section{MATERIAL E MÉTODOS}

o experimento fai conduzido no Setor de Suinocultura do Departamento de Zootecnia, da Escola Superior de Agricultura "Luiz de Queiroz", Universidade de São Paulo, em Piracicaba, SP, envolvendo um total de 70 leltóes das racas Landrace, Large White e Duroc, puros e mesticos, com peso médio inicial de $10,38 \mathrm{~kg}$.

A creche experimental era equipada com 20 gaiolas metálicas suspensas, com dimensão de $1,50 \times 1,20 \mathrm{~m}$. Esta instalacão possuia bebedouro tipo chupeta e comedouro automático.

A Tabela 1 apresenta a composicão química e a energia digestível dos ingredientes da racão. Já a Tabela $z$ apresenta a composicão percentual da ração basal.

A virginiamicina foi incorporada a racão basal, com $18 \%$ de P.B. e $3.337 \mathrm{kcal}$ ED/kg, em cinco distintos niveis: $0,25,50,75$ e $100 \mathrm{ppm}$.

A água e as racóes peletizadas foram fornecidas a vontade aos animais, durante os 28 dias no período experimental. Tanto os pesos individuais quanto os dados de consumo de racão foram coletados semanal mente durante todo o experimento. A conversão alimentar foi obtida a partir da 
29.

ingestão total da racão e ganho de peso, no periodo consi derado.

- delineamento experimental foi o de blocos casualizados, com seis repeticóes/tratamento, de acordo com a raca, o peso e o sexo. Cada unidade experimental era representada por uma baila com 2 ou 3 animais.

Tabela 1 - Composicão Química e Energia Digestivel dos Ingredientes".

\begin{tabular}{|c|c|c|c|c|c|}
\hline \multirow{2}{*}{ I TENS } & \multicolumn{5}{|c|}{ INGREDIENTES } \\
\hline & $\begin{array}{ll}M I L H O & F A \\
D E\end{array}$ & $\begin{array}{l}\text { RELO } \\
\text { SOJA }\end{array}$ & ACÚCAR B & $\begin{array}{l}\text { FOSFATO } \\
\text { BICÁLCICO }\end{array}$ & $\begin{array}{l}\text { CARBONATO } \\
\text { DE CALCIO }\end{array}$ \\
\hline M.S. , \% & 87,00 & 86,93 & 99,69 & - & - \\
\hline P.B. , $\%$ & 7,76 & 42,69 & 0,08 & - & - \\
\hline F.B. , \% & 2.03 & 6.48 & - & - & - \\
\hline E.E. , \% & 3,20 & 1,95 & - & - & - \\
\hline M.M. $\%$ & 0.91 & 5,68 & - & - & - \\
\hline E.N.N. , $\%$ & 73,10 & 30,15 & 99,07 & - & - \\
\hline $\mathrm{Ca}, \%$ & 0,01 & 0,32 & - & 26,00 & 39,50 \\
\hline$P, \%$ & 0,20 & 0,55 & - & 19,00 & - \\
\hline Lisina, $\%^{b}$ & 0,24 & 2,57 & - & - & - \\
\hline Triptofano, $\%^{b}$ & 0.06 & 0.80 & - & - & - \\
\hline Metionina+Cistina, $\%^{b}$ & 0,33 & 1.02 & - & - & - \\
\hline E. D. $\mathrm{kcal} / \mathrm{kg}^{\mathrm{b}}$ & 3.460 & 3. 448 & 3. 955 & - & - \\
\hline
\end{tabular}

GLaboratorio de eromatologia do Departamento de zoolecnia - EsAlarusp. EMPRESA BRASILEIRA DE PESQUISA AOROPECUARIA 11089 ). 
Tabela 2 - Composicão Percentual da Racão Basal.

\begin{tabular}{lr}
\hline INGREDIENTES & $\%$ \\
\hline Milho & 62,20 \\
Farelo de Soja & 30,86 \\
Afúcar & 4,00 \\
Fosfato Bicálclco & 1,87 \\
Carbonato de Cálcio & 0,40 \\
Sal & 0,50 \\
Premix de Vitaminas & 0,07 \\
Premix de Microminerais & 0,10 \\
- &
\end{tabular}

Valores Calculados:

E. D. , kcal $\mathrm{kg}$

3. 337

P.B. , \%

18,00

$\mathrm{Ca}, \%$

0,75

P, \%

0,65

Lisina, \%

1,03

Iriptofano, $\%$

0,26

Metionina + Cistina, \%

0,63

asuprindo as seguintesquantidades por $\mathrm{kg}$ de racão:

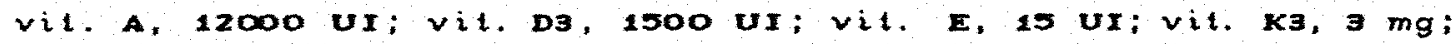

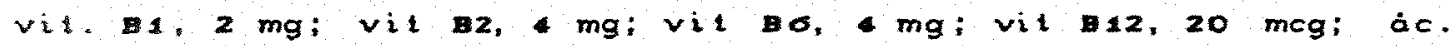

nicolinico, $20 \mathrm{mg}$; ac. tólico, o, 00 mgi ác. pantolönico, 15 mg;

biotina, $100 \mathrm{mcg}$.

b.

suprindo as seguintesquantidades por kg de racá

Fo $120 \mathrm{mg} ; \mathrm{Cu}, 21 \mathrm{mg} ; \mathrm{Mn}, 50 \mathrm{mg} ; \mathrm{Zn}, 00 \mathrm{mg} ; \mathrm{I}, 2,0 \mathrm{mg} ; \mathrm{Co}, 2, \mathrm{mg}$

Ao final do experimento e após um jejum de 5 horas, foram coletadas amostras de sangue da veia cava anterior de todos os animais em seringas de $10 \mathrm{ml}$. Imediatamente após a coleta, cada amostra era transferida para um tubo de ensaio que continha $0,10 \mathrm{ml}$ de EDTA $10 \%$ Logo após uma homogeinização lenta e cuidadosa, cada amostra foi 
dividida em duas sub-amostras e mantidas em gelo para posterior manuseio em 1 aboratório.

De uma das sub-amostras, separou-se o plasma por centrifugacáo a $5.000 \times \mathrm{g}$ por $20 \mathrm{minutos.} \mathrm{Em} \mathrm{seguida,}$ foram preparadas amostras compostas do plasma dos leitões pertencentes a uma baia crolumes equivalentes do plasma de cada animall que correspondia a uma unidade experimental.

A outra sub-amostra de sangue e as amostras compostas de plasma foram mantidas em refrigerador por 24 horas e, então, enviadas para o Laboratório Previav - Centro de Patologia Clínica Preventiva Ltda., Piracicaba - SP, para análise dos componentes sanguíneos chematócrito e hemoglobina) e componentes plasmáticos (proteína total, albumina, uréia triglicerídioss. Os niveis de globulina foram obtidos por diferenca entre a proteína total a a albumina. Uma vez calculado o conteúdo de globul ina do plasma, póde-se determinar a relacão albumina/globulina.

Os dados do experimento foram submetidos à análise de variância, sendo que os graus de liberdade dos tratamentos foram decompostos em seus componentes individuais de regressão Clinear. quadrática, etc.... através dos polinômi os ortogonais, conforme STEEL \& TORRIE (1980). Esta análise foi realizada no Centro de Informática na Agricultura - CCIAGRIS - ESALQ USP, através do programa de Sistema de Análise Estatística - SANEST. 


\section{RESULTADOS E DISCUSSÃO}

\subsection{Caracteristicas de Performance}

As médias das características de performance dos leitós, avaliados com base no consumo diário de racão (CDR), ganho diário de peso (GDP) e conversão al imentar (CA), bem como os resultados da análise de variância e coeficientes de variacão CCV\% são apresentados na Tabela 3. Os valores originais dos dados de performance, correspondentes aos cinco diferentes níveis de virginiamicina, se encontram na Tabela Al do Apêndice.

A virginiamicina proporcionou tendências a uma resposta quadrática $C P<0,20)$ do ganho diário de peso CGDP = $0,4676520+0,0015645 x-0,0000116 x^{2}$ e também quadrática $C P<0,10)$ do consumo diário de ração $C$ CDR $=0,904048+$ $0,002676 x-0,000025 x^{2}$. A conversão alimentar, por sua vez, foi I inearmente $C P<0,012$ melhorada pelo antibiótico $C \mathrm{CA}=$ $1,93933-0,00104 \times$, onde $x$ representa o nivel de virginiami cina na racão. Tais respostas são representadas na figura 2.

A equação do GDP permitiu estimar o nível de 67,4 ppm de virginiamicina na dieta, como o mais adequado para a máxima resposta desta característica. 
33.

Tabela 3 - Médias das Características de Performance de Suínos em Recria, Al imentados com Racão Contendo Niveis Grescentes de Virginiamicina ${ }^{a}$.

\begin{tabular}{|c|c|c|c|c|c|c|}
\hline \multirow{2}{*}{ I TENS } & \multicolumn{5}{|c|}{$\begin{array}{c}\text { NI VEIS DE VIRGINI AMI CINA } \\
(\mathrm{pPm})\end{array}$} & \multirow{2}{*}{$\underset{\%}{c . v .}$} \\
\hline & 0 & 25 & 50 & 75 & 100 & \\
\hline Número Animais & 14 & 14 & 14 & 14 & 14 & - \\
\hline Periodo, dias & 28 & 28 & 28 & 28 & 28 & - \\
\hline Peso Médio Inicial, $\mathrm{kg}$ & 10,231 & 10,401 & 10,391 & 10,521 & 10,37 & 1,58 \\
\hline Peso Médio Final, $\mathrm{kg}$ & $23,38=$ & $24,25=$ & $25,00 \%$ & 24.972 & 24,83 & 0,00 \\
\hline Cons. Diário Ração, $\mathrm{kg}^{\mathrm{b}}$ & 0,90 & 0.97 & 0.98 & 0.94 & 0,941 & 10,53 \\
\hline Ganho diário Peso, $\mathrm{kg}^{\mathrm{C}}$ & 0,489 & 0,495 & 0.523 & 0,516 & 0,508 & 9,07 \\
\hline Conversão Al i mentar ${ }^{d}$ & 1,98 & 1,96 & 1,88 & 1,83 & 1,85 & 3,96 \\
\hline 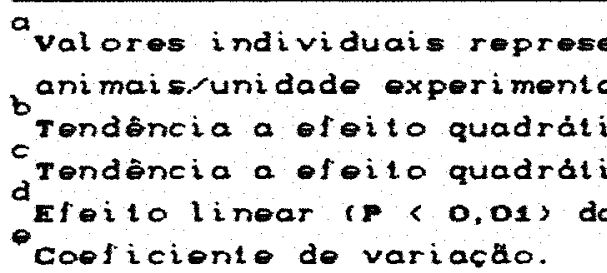 & $\begin{array}{l}\text { lam modi } \\
\text { lblocos } \\
0 \text { ip } \\
\text { if } \\
\text { virainio }\end{array}$ & $\begin{array}{l}i a \text { de } 2 \\
5=0 . \\
0,10 \text { s. } \\
0,20 \text { s. } \\
\text { amicina. }\end{array}$ & blocos & $1,2,3$ & -4a & 3 \\
\hline
\end{tabular}


34.

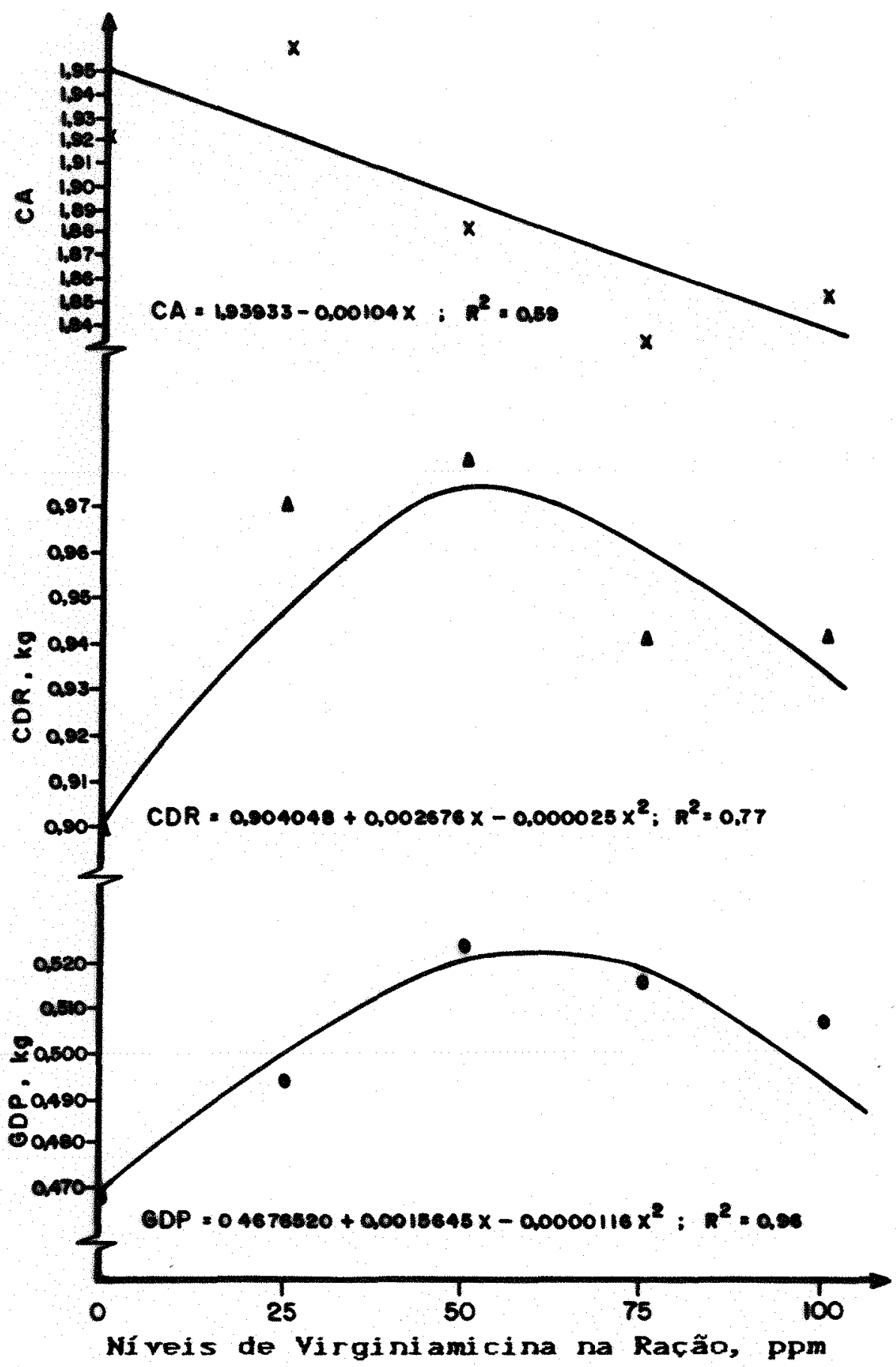

Figura Z - Efeitos da Virginiamicina sobre a Performance de Suínos em Recria CCA = Conversão Alimentar; CDR = Consumo Diário de Racão: GDP = Ganho Diário de Pesol. 
35.

Embora as diferencas não tenham sido significativas $(P) 0,05)$, na realidade, os ganhos diários de peso dos animais recebendo racões com $25,50,75$ e 100 ppm de virginiamicina foram, respecti vamente, $5,54 \%, 11,51 \%, 10,02 \%$ e $8,32 \%$ maiores do que o dos animais controle. VERVAEKE et alii (1979), também observaram apenas tendência a melhora do GDP para suinos em crescimento recebendo o antibiótico virginiamicina. Em contrapartida, JONES \& POND (1963) observaram aumentos significativos neste parámetro com a utilizacão de 20 ppm do antibiótico em racões de leitóes desmamados. HAYS et alii (1973), trabalhando com suínos em crescimento ( 19 aos $57 \mathrm{~kg}$ ), também obtiveram mel horas significativas $(P<0,05)$ no GDP de, respectivamente, 8,96 13,98\%, quando do uso de níveis dietéticos de 22 e 88 ppm de virgini ami cina.

Em experimentos desenvol vidos por BELLAVER et alii (1982) e RIBEIRO et ali $(1984)$, foi observado que a virginiamicina não afetou significativamente o GDP. Contudo, os níveis de 10 e 20 ppm deste antibiótico proporcionaram aumentos de, respectivamente, 2,00 e $8,89 \%$ no GDP dos suínos. Segundo estes mesmos autores, o resultado obtido sugere que os antibióticos exercem efeitos benéficos no crescimento devido a acão sobre os microrganismos do trato intestinal e não devido ao aumento de consumo dos animais. PACHECO et ali (1988) também não observaram melhoras significativas no GDP e na CA, quando do uso de $10 \mathrm{ppm}$ de Virginiamicina sozinha ou combinada com bacitracina de zinco 
36.

em raçóes de suínos em crescimento-terminacão. A ausência de beneficios da virginiamicina na performance destes animais pode estar relacionada justamente com sua baixa dosagem, pois de acordo com BELLAVER et alii (1982), somente niveis mais elevados do produto é que são capazes de promover aumento da taxa de ganho de peso melhoria da eficiencia al i mentar.

Os leitóes que receberam racŏes com $25,50,75$ - 100 ppm de virginiamicina apresentaram, respectivamente, valores de consumo diário de racão $7,78,8,89,4,44$ e $4,44 \%$ maiores do que o dos animais controle, embora tais diferencas não tenham sido significati vas $(P>0,05)$. 0 máxi mo consumo dos leitóes, determinado com base na equacão já citada anteriormente, foi obtido com 53,5 ppm do antibiótico na racão. RIBEIRO et alii (1984), também trabal hando com suínos em recria, determi naram que o maior nivel utilizado em seu estudo C 20 ppm, apesar de não significativo, resultou em aumento de $6,69 \%$ no consumo de racão dos ani mais.

Neste experimento, a conversão alimentar foi Iinearmente $C P\langle 0,01\rangle$ melhorada pela adicão de virginiamicina na racão. Os niveis de 50,75 e 100 ppm deste antibiotico proporcionaram melhorias na conversão alimentar de, respectivamente, 2,$1 ; 4,7 \odot 3,6 \%$ Entretanto, o nivel de 25 ppm acarretou uma piora de $2,08 \%$

As possiveis explicacóes para a obtencão de respostas benéficas na conversão alimentar são: 
- possivel contrale da quantidade de bactérias competidoras com o hospedeiro Csuinos pelos nutrientes:

- a diminuicão da espessura da parede do trato intestinal;

- aumento da permeabilidade da mucosa intestinal, ou também devido a uma combinacão de dois ou mais destes mecanismos.

HAYS et alii (1973), trabal hando com suínos em crescimento, recebendo na racão 0,22 ou 88 ppm de virginiamicina, também encontraram melhora significativa $C P(0,05)$ na $C A$ de 3,06 (1,14\%, respecti vamente $(2,94 \times 2,85 \times 2,73)$. RUSSET et alii (1976) também encontraram meIhorias significativas $(P<0,05)$ da CA devido a adicão de 55 fpm de virginiamicina na racão das suinos em fase inicial. Da mesma forma, HAYS et alii (1973) observaram que durante a fase inicial dos suinos, a resposta a virginiamicina foi uma melhora de $5 \%$ na $C A$, enquanto que, na fase de crescimento, o benefício foi de 6,6\%. Também PELURA et ali (1980) afirmaram que suinos, recebendo a virginiamicina na fase inicial de vida, apresentaram melhoras de 3,0 e $42 \%$ da taxa de CA em dietas contendo, respectivamente, $18 \%$ de $P B$ e 15\% PB mais lisina. Tal fato pode estar relacionado a economia de energi a liquida já devidamente postulado por VERVAEKE et alii (1979). De acordo com BELLAVER et alii (1982), o benefício obtido com o uso de 10 ppm de virginiamicina, da 
38.

fase inicial até a terminacão, foi de $2,1 \%$ para a CA.

\title{
4. 2. Componentes Sanguíneos e Plasmáticos
}

\begin{abstract}
A Tabela 4 apresenta as médias dos componentes sanguineos (hematócrito e hemoglobina) e plasmáticos (uräia, albumina, globulina, relacão abumina/globulina, proteína total e trigliceridios, dos leitôes, assim como as respectivas análises de variância e coeficientes de variacão CC.V.\%. Os valores originais dos resultados dos componentes sanguineos - plasmáticos dos suinos em recria alimentados com racão contendo niveis crescentes de virginiamicina encontram-se na Tabela AZ do Apêndice.
\end{abstract}

O hematócrito, a hemoglobina e as conteúdos de albumina, uréia e trigliceridios não sofreram influência significativa $(P) 0,05)$ dos niveis de virginiamicina na ração.

- valor do hematócrito, segundo POND \& MANER (1974), juntamente com o de hemoglobina, são parâmetros indicadores do estado nutricional dos suŕnos quanto ao nutriente ferro. Os valores médios obtidos neste experimento (31,84\%, $10,01 \mathrm{~g} / \mathrm{dl}$, respectivamente) estão de acordo com aqueles considerados normais $(30-45 \%$ e 9,6 g/dl, respectivamente) (POND \& MANER, 1974$).$ 
39.

Tabela 4 - Média dos Componentes Sanguíneos e Plasmáticos de Suínos em Recria, Al imentados com Racóes Contendo Ní veis Crescentes de Virginiamicina.

\begin{tabular}{|c|c|c|c|c|c|c|}
\hline \multirow{2}{*}{ I TENS } & \multicolumn{2}{|c|}{ NIVEIS DE } & \multicolumn{3}{|c|}{$\begin{array}{l}\text { VIRGINI AMI CINA } \\
\text { CPPM }\end{array}$} & \multirow{2}{*}{ c. $v^{\circ}$} \\
\hline & 0 & 25 & 50 & 75 & 100 & \\
\hline Nümero Animais & 14 & 14 & 14 & 14 & 14 & - \\
\hline Período, dias & 28 & 28 & 28 & 28 & 28 & - \\
\hline Peso Médio Inicial, $\mathrm{kg}$ & 10,23 & 10,40 & 10,39 & 10,52 & 10,37 & 1.58 \\
\hline Peso Médio Final, kg & 23,36 & 24,25 & 25,02 & 24,97 & 24,63 & 0.00 \\
\hline
\end{tabular}

Componentes sanguineos ${ }^{a}$

Hematócrito, $\%$

$31,5 \quad 32,8 \quad 32,3 \quad 32,3 \quad 30,4 \quad 10,24$

Hemogl obina, g/dl

$9,9210,3810,1710,10 \quad 9,5010,91$

Componentes plasmáticos ${ }^{a}$

Proteina Total, $\mathrm{g} / \mathrm{dl} \mathrm{b}^{\mathrm{b}} \quad 5,57 \quad 5,72 \quad 5,62 \quad 5,78 \quad 5,98 \quad 4,58$

Albumina, $g / d l \quad 2,82 \quad 2,92 \quad 3,00 \quad 2,83 \quad 2,90 \quad 4,28$

Globulina, $g^{\prime} d^{c} \quad 2,92 \quad 2,80$ 2,62 2,95 3,08 10,26

Albuminatglobulina d $0,991,07 \quad 1,17 \quad 0,97 \quad 0,9613,29$

Uréia, mg/dl $23,5 \quad 22,8 \quad 23,7 \quad 22,7 \quad 24,7 \quad 18,92$

Trigliceridios, $\mathrm{mg} / \mathrm{dl} \quad 50,3 \quad 53,3 \quad 40,7 \quad 48,8 \quad 44,7 \quad 19,99$

avalores individuai reprementam media de 2 bblocas $1,2,3$, ou 3

animais (blocos $s$ os por unidade experimental.

bendencia a efoito quadralico \& $<0,00$ dos niveis de virginiamicina.

Efeilo quadratico $(P<0, \infty)$ dos nivei de virginiamicina.

Efeito quedralico (P $(0, \infty)$ dos niveis de virginiamicina.

coeficierte de variacto.

Com relacão à proteína total do plasma, houve uma tendência $C P<0,090$ a uma resposta quadrätica $C P_{t}=$ $\left.5.75333-0.00573 x+0.00008 x^{2}\right)$. como ilustra a Figura 3. 
Esta referida equacäo permitiu estimar um nivel de 35,8 ppm de virginiamicina como o mais adequado para tal parâmetro.

o nivel de proteina total, encontrado neste experimento, corresponde ao nivel considerado como normal citado por POND \& HOUPT (1980), o qual varia em torno de $5,0-7,0 \mathrm{~g} / \mathrm{dl}$ de plasma de suínos em fase de recria c5 - 10 semanas?.

O nivel de albumina dos animais recebendo virginiamicina na racăo foi maior do que dos animais controle. A média deste parámetro foi de 2,90 contra 2,82 dos animais controle, embora tal diferenca năo tenha sido significativa. De acordo com MILLER et alii (1961) o nível de albumina sérica permanece constante atraves da vida do suíno após estes atingir o pico máximo à terceira semana de vida, sendo responsável pela manutencão do volume plasmătico.

A virginiamicina determinou respostas quadráticas $C P<0,03)$ do conteúdo plasmático de globulina $C$ GLO = $\left.=2,9219050-0,0096857 x+0,0001162 x^{2}\right)$ e da relação albuli na/globul ina CALE/GLO $\left.=0,994048+0,004898 x-0,000052 x^{2}\right)$ Estas respostas do contéudo plasmático de globulina e de relacão albumina/globulina à adicão de virginiamicina na ração, estão ilustradas na figura 3 . os níveis de virginiamicina observados como os mais adequados a estes parámetros foram os de 41,7 e 44,5 ppm, respectivamente, como possivel verificar através das equacões acima apresentadas, SMITH et alii (1960) MLLER et alii (1961) relataram que para suinos em idade de abate e para suinos de até trés meses de 
idade o valor normal da relacão albumina/globulina é de 1,20 0,40-1,01 respectivamente. POND \& HOUPT (1980) relataram valores de 0,8 para suinos recém-nascidos e 1,0 para suínos adultos.

o valor de uréia encontrado no plasma animal, - um indicador do balanco de aminoácidos da racão. Sendo que um elevado valor deste componente indica um aumento do catabolismo dos aminoácidos que encontram-se em excesso na dieta CPUCHAL, 1962). Isto conduz a uma baixa performance animal, ou seja, baixo ganho de peso o baixa eficiencia alimentar, que pode ser devido a excessiva quantidade de froteina ingerida erou de proteina de baixo valor biológico.

Portanto, o fato do nível de uréia não ter sido influenciado $(P>0,05)$ pela adicão do antibiótico na racão, indica que a racão foi adequadamente balanceada, $\theta$ que a virginiamicina năo interferiu no catabolismo da fracão protélca da racão.

O nivel de trigliceridios não foi influenciado $(P>0,05)$ pela virginiamicina adicionada à racăo. Entretanto, os dados apresentados na Tabela 4 mostram que com a adicão de 25 ppm do antibiótico ocorreu uma elevacão de $6 \%$ no conteúdo de triglicerídios no plasma dos suínos, enquanto que os demais níveis de 50,75 , 100 ppm promoveram uma reduça de respectivamente, 19,$1 ; 3,0 \Leftrightarrow 15,5 \%$ A análise estatistica não detectou diferencas significativas devido, possivelmente, a uma variabilidade muito elevada, conforme mostra o coeficiente de variacão de $19,99 \%$ 
42.

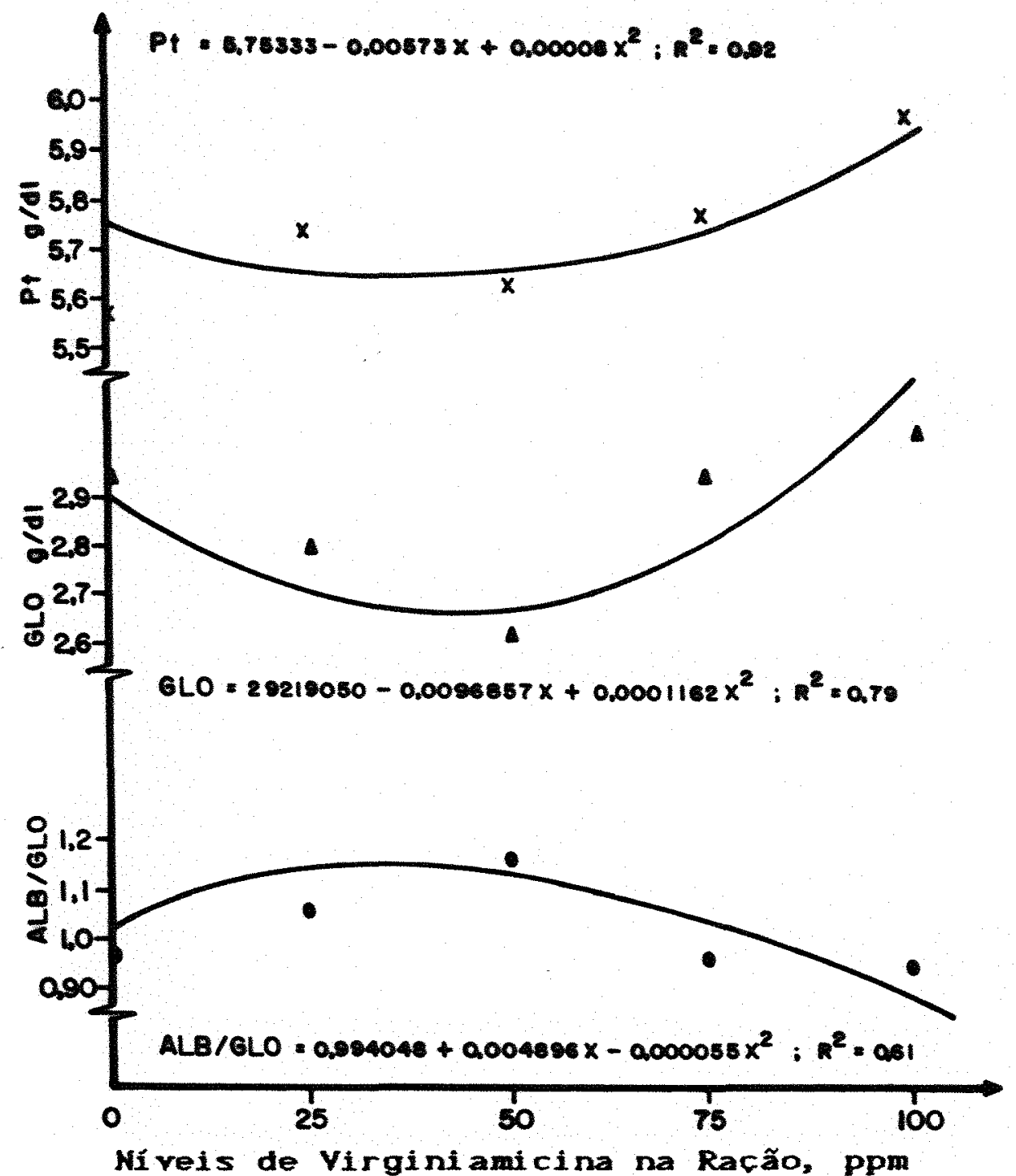

Figura 3 - Efeitos da Virginiamicina sobre a Proteína Total, Globulina Relacão Albumina/Globulina do Plasma de Suínos em Recria Alimentados com Racão Contendo Niveis Crescentes de Virginiamicina. 
43.

\section{CONCLUSÃO}

A adicão da virginiamicina ate o nivel de 100 ppm na racão de leitóes em recria proporcionou tendências a respostas quadráticas do ganho diário de peso e do consumo diário de racão. As equacões de tais respostas permitiram determinar um nivel médio de 60 ppm de virginiamicina como o mais adequado para estas duas caracteristicas. Por outro lado, a conversão alimentar dos leitốes foi linearmente melhorada até 100 ppm do antibiótico na raç̃o.

o hematócrito, a hemoglobina e os conteúdos plasmáticos de albumina, uréia e triglicerídios não foram influenciados pela virginiamicina. Contudo, as respostas da proteina total, globulina e relação albumina globulina permitiram estimar um nivel médio adequado de 40 ppm deste antibiótico em racão de leitões en recria.

Assim, os resultados deste experimento evidenciaram o efeito promotor do crescimento da virginiamicina em leitốes em recria. 


\section{REFERENCI AS BI BLI OGRÁFICAS}

ABOU-YOUSSEF, M.H. ; CUOLLO, C.J.; MILLER, C.R. ; SCOTI, G. C. Influence of a sub-therapeutic level of virginiamycin in feed on the incidence and persistece of Salmonella typhemurium in experimentally infected swine. Journal of Animal Science, Champaing. 49(1): $128-33$, Jul y 1979.

ADAMS, R.L. \& LARSON, J.E. Effect of feeding virginiamycin with and without roxarsone in the presence of salinomycin to broiles on weights, feed conversion and eviscerated yields. In: PACE SETER CONFERENCE, Atlanta, 1980 . 5.1., Smith Kline, 1986. p. 1-1E.

ALESSANDRO, C. Os antibióticos na alimentacão dos suínos. Brasil Oeste, São Paulo, 7(67): 16-7, Mar. 1962.

BARBER, R.S. BRAUDE, R.; MITCHELL, K. G.; PITIMAN, R. J. The value of virginiamycin (eskalin) as a feed addictive for growing pigs in diets with or without a high copper supplement. Animal Production, Edinburgh, 26: $151,1978$.

BELLAVER, C.; COMES, P.C.; COSTA, V.; FIALHO, E. T.; FREI TAS, A.R. Cobre virginiamicina como promotores de crescimento de suínos. Pesquisa Agropecularia Brasileira, Brasilia, 17(12): 1789-93, Dez, 1982

BRAUDE, R. Antibiotics in animal feeds in Great Britain. Journal of Animal Science, Champaing, 46(5): 1425-36, May $1978 a$. 
BRAUDE, R. Use of feed addictives in E. A. A.P. member countries - a survey. Livestock Production Science, Ansterdam, $5(3): 237-44$, Jul y $1978 b$.

CAON, A.P. Breve estudo e emprego dos principais antibióticos em veterinária. Boletim da Diretoria da Producão Animal, Porto Alegre (22): 128 , Maio 1955.

CLAWSON, A.J. \& ALSMEYER, W. L. Chemotherapeutics for pigs. Journal of Animal Science, Champaing, 37(4): 918-26, oct. 1973.

CLEMMER, R. A. \& SEERLEY, R. M. The effect of calorie lysine ratio season, and virginiamycin on growing-fishing swine performance carcass caracteristics and nutrient digetibi 1ities. In: ANMUL MEETING OF THE AMERICAN SOCIETY OF ANIMAL SCIENCE, 76, Nashville, 1984. Abstracts. Journal of Animal Science, Champaing, 59(supl 1): 49, Feb. 1984.

COCITO, C. Metabolism of macromolecules in bacteria treated with virginiamycin. Journal of Genetic Microbial, London, 57: $179-94$, Aug. 1969.

COMBS, G.F. \& BOSSARD, E.H. Comparison of growth response of chiks to virginiamycin and other antibiotics. Poultry Science, Ontario, 42(1): 681-5; 1963

COOK, R.E. \& ORT, J.F. Virginiamycin in broiler diets. In: WORLD'S POULTRY CONGRESS, 17, Nagoya, 1988. Proceedings. 5.1. Japan Poultry Science Association, 1988. p. 843-5.

CRAMFORD, L.M. Virginiamycin. In:

Antibiotics Sulfanamides and Public Health. Boca raton, CRD Press, 1984. P. 345-9. CRC Handbook Series in Zoonoses, 1. 
CUNHA, T.J. Antibiotics ansd other antimicrobial compounds. In: Swine Feeding and Nutrition. London, Academic Press, 1977. Cap 9, p. $191-201$.

CUOLLO, C.J. Establishment of human safety for virginiamycin when employed as performance promoter and virginiamycin's i mpact on the environment. In: ROUND TABLE OF PERFORMANCE IN ANIMAL PRODUCTION, Milão, 1979. Anais. 5.1., 1979 p. $321-38$.

EMPRESA BRASI LEI RA DE PESQUISA AGROPECUÁRIA. Centro Naci onal de pesquisa de Suínos e Aves. Tabela de composicẫo química valores energéticos de alimentacão para suinos aves. 3 ed. Concórdia, 1989 . (EMBRAPA - CNPSA).

ENSMINGER, M.E. \& OLINTINE, O.S. Feed suplements, additives, implantes. In:

Feeds and Nutrition. Clovis, The Ensminger Publ., 1980. Cap. 13, pt. 2, p. 411-36.

EYSSEN, H. \& DE SOMER., P. Effects of Stroptococcus faecalis and a filterable agent on growth and nutrient absortion in gnotobiotic chicks. Poulty Science, Champaing 46: $323-33,1967$.

HARPER, A.F. \& KORNEGAY, E.T. The effects of restricted floor space allowance and virginiamycin supplementation on the feedlot performance of swine. Livestock Production Science, Amsterdam, 10: $397-409,1983$.

HARPER, A.F; KORNEGAY, E.T.; BRYANT, K.L.; THOMAS, H.R. Efficacy of virginiamycin and a commercially availabe lactobacillus probiot in swine diets. Animal Feed Science and Technology, Amsterdam, B(1): 69-76, 1983.

HAYS, V.W. \& MUIR, W.M. Efficacy and safety of feed additive use of antibacterial orugs in animal production. 
Canadian Journal of Animal Science, Otawa, 59(2): 447-56, June 1979.

HAYS, V.W.; LANGLOIS, B.E. ; CROMWELL, G.L. Effect of virginiamycin on performance of pigs. In: ANNUAL MEETING OF THE AMERICAN SOCIETY OF ANIMAL SCIENCE, 65, 5.1, 1973. Abstracts. Journal of Animal Science, Champaing, $37(1)$ : $281,1973$.

HOPPE, M.K.; HAMILTON, C.R.; BORG, B.S.; LIBAL, G. W. WAHLSTROM, R.C. Effects of grain source and antibacterial agents (virginiamycin or bacitracin disalicylate) on grower-finisher pigs. In: ANNUAL MEETING OF THE AMERICAN SOCIETY OF ANIMAL SCIENCE, 80, New orleans, 1988. Abstracts. Journal of Animal Science, Champaing, 66csupl. 1): $128-9$, Feb. 1988.

HOWELING, C.D. van \& GAINER, I.H. Public health concerns relative to the use of subtherapeutic levels of antibiotics in animal feeds. Journal of Animal Science, Champaing, $46(5): 1413-24$, May 1978 .

JONES, J.R. \& POND, W.G. Effect of the addition of lysine and virginiamycin to corn soybean meal rations on performance of weanling pigs. Journal of Animal Science, $22(4) ; 1033-7$, Nov. 1963.

JONES, R.W. \& EASTER, R. A. The influence of antibiotics on the growing and fishing pigs fed diets containing corn gluten feed. In: ANNUAL MEETING OF THE AMERICAN SOCIETY OF ANIMAL PRODUCTION, 78, Orlando, 1986. Abstracts. Journal of Animal Science, Champaing, 63 (supl. 1): 269, Feb. 1986.

KRIDER. I.L.; PLUMLEE, M.P.; RUSSET, I.C.; HARRINGTON, R. B. : UNDERWOOD, L. B. Virginiamycin responses of young 
48.

pigs fed to market weights. In: ANNUAL MEETING OF THE AMERICAN SOCIETY OF ANIMAL SCIENCE, 67, Fort Collins, 1975. Abstracts. Journal of Animal Science, Champaing. $41(1): 318-9$, July 1975.

KUTHER, K.H. Experiências com virginiamicina na alimentacão de aves na Alemanha. In: SIMPÓSIO BRASILEIRO DE VIRGINIAMI CINA, 2, Rio de janeiro, 1881. Rio de Janeiro, Smith Kilme, 1981 . p. $13-24$.

LANGLOIS, B.E.; CROMWELL, G.L.; HAYS, V.W. Influence of type of antibiotic and lenght of antibiotic feeding period on performance and persistence of antibiotic resistance enteric bacteria in growing-finishing swine. Journal of Animal Science, Champaing, 46C5): 1383-96, May 1978.

MAYNARD, L.A.; LOOSLI, J.K.; HINTS, H.F. ; WARNER, R. G. Animal Nutrition. 7 ed. New York, McGraw-Hill Book, 1979. $590 p$.

MENTEN, J.F.M. Effect of high dietary copper on the utilization of nutrients and on blood and intestinal variables of starter pigs. Michigan, 1988 . $122 \mathrm{p}$. (PhD-Michigan State University).

THE MERCK index, an encyclopedia of chemicals and drugs. 9 ed. Rahway, Merch, 1976.1937 .

MILLES, R.D. Influência da virginiamicina na al imentação de frangos e poedeiras. In: SIMPÓSIO BRASILEIRO DE VIRGINI AMI CINA, 2, Rio de Janeiro, 1961 . Rio de Janeiro, Smith Kline, 1981 . p. 9-12.

MLLER, E.R.; HITCHKOCK, J.P.; ORR, D.E.; ULLREY, D.E. Virginiamycin for growing finishing pigs. In: ANNUAL 
49.

MEETING OF THE AMERICAN SOCIETY OF ANIMAL SCIENCE, Chicago, 1972. Abstracts. Journal of Animal Science, Champaing, 35(5): 1108 , Nor. 1972.

MILLER, E.R. ; ULLREY, D.E. ; ACKERMAN, I.; SCHMIDT, D. A. ; HOEFER, J.A. ; LUECKE, R.W. Swine hematology from birth to maturity. I. Sorum proteins. Jounnal of Animal Science, Champaing, 20(1): 31-5, Feb. 1901.

MOSER, R.L.; CORNELIUS, S.G.; PETTIGREW JUNIOR, J.E.; HANKE, H. E. : HAGEN, C. D. Response of growing finishing pigs to decreasing floor space allowance and cors virginiamycin in diet. Journal of Animal Science, Champaing, 61(2): 337-42, Aug. 1985.

NATIONAL RESEARCH COUNCIL. Committe on Confinament Management of Swine. Effect of space allowance and antibiotic feeding on performance of nursery figs. Journal of Animal Science, Champaing, 58( 4): 301-4, Apr. 1984.

PACHECO, C.R.V.M. ; FERREIRA, A.S.; COSTA, V. Efeitos de virginiamicina e zinco bacitracina no desempenho de suínos em crescimento e terminação. Revista da Sociedade Brasileira de Zootecnia, Vicosa, 17(2): 172-9, Mar. Atar. 1988.

PELURA III, J. KRIDER, J.L. ; CLINE, T.R. Virginiamycin, protein and lysine responses of young swine. Journal of Animal Science, Champaing, 50(5): 767-72, May, 1980.

POND, Y.G. \& HOUPT, K.A. Fluidos corporales hematologia e inmunologia. In: Biologia del cerdo. Zaragoza, Acribia, 1980 . cap 8, p. 223-39. 
50.

POND, W. G. \& MANER, J.H. Swine Production in Temperature and Tropical Environments. San Francisco, W. H. Freeman, 1974. $646 \mathrm{p}$.

PUCHAL, F.; HAYS, V.W.; SPEER, V.C.; JONES, J.D. The free blood plasma amino acids of swine as related to the source of dietary proteins. Journal of Nutrition, Bethesda, $76(1) ; 11-16, J a n .1902$.

RAVINDRAN, V.; KORNEGAY, E. I.; WEBB, J.R., K. E. Effect of fiber and virginiamycin on nutrient absorption, nutrient. retention and rate of passage in growing swine. Journal of Animal Science, Champaing, 59(2): 400-8, Aug. 1984.

RIBEIRO, U.F.F.; KRONKA, R.N.; BUTOLO, J.E. Efeitos da virginiamicina no desenvolvimento e características de carcaca de suínos. Pesquisa Agropecuária Brasileira, Brasilia, 19(5): 651-6, Maio 1984 .

RUSSET, J.C. KRIDER, J.L. ; PLUMLEE, M.P.; UNDERWOOD, L. B. High levels of virginiamycin for growing swine. In: ANNUAL MEETING OF THE AMERICAN SOCIETY OF ANIMAL SCIENCE, 10, Champaing, 1976. Abstracts. Journal of Animal Science, Champaing, 42(5):1357-8, May 1976 .

SMI TH, I.D.; HOEKSTRA, \%. G.; GRUMMER, R.H.; PHILLIPS, P.H. Studies on the sorum proteins of normal and parakeratotic pigs. Journal of Animal Science, Champaing, 19(2): 580-9, May 1960.

SMI THKLINE. Virginiamycin technical manual. s.1. 1977. 80 p. SOLOMONS, I.A. Antibiotics in animal feeds-human and animal safety issues. Journal of Animal Science, Champaing. 46(5): $1360-8$, May 1978. 
STAHLY, T.S.; CROMWELL, G.L.; MONEGUE,H.J. Effects of the dietary inclusion of copper and or antibiotics on the performance of wealing pigs. Journal of Animal Sclence, Champaing, 51(8): 1347-51, Dec. 1980.

STEEL, R.D.G. \& TORRIE, J.H. Principles and procedures of statistics; a Blometrical Approach. $Z$ ed. New York, McGraw Hill, 1980 . $804 p$.

VERVAEKE, I.J.; DECUYPERE, J.A. ; DIERICK, N. A. ; HENDERICKX, H.K. Quantitative in vitro evaluation of the energy metabolism influenced by virginiamycin and spiramycin used as groth promoter in pig nutrition. Journal of Animal Science, Champaing, 49(3): 846-56, Sept. 1979.

VISEK, W.J. The mode of growth promotion by antibiotics. Journal of Animal Science, Champaing, 46(5): 1447-69, May, 1978.

WALLACE, H.D. Biological responses to antibacterial feed additives in diets of meat producing animals. Journal of Animal Science, Champaing, 31(6): $1118-26$, June 1970.

WHITE, C.E.; LOPEZ, F.D.; MYER, R. O.; GORBERT, D. W. Evidence for a growth depressing interation when fat and virginiamycin are combined in diets fed to swine. In: ANNUAL MEETING OF THE AMERICAN SOCIETY OF ANIMAL SCIENCE, 80, New orleans, 1988. Abstracts Journal of Animal Science, Champaing. 66 (supl. 1): 318, Jan. 1988. 
52

APENDICE 
Tabela A1 - Peso Médio Inicial CPMI, kgl, Peso Médio final (PMF, $\mathrm{kg}$, Consumo Di ário de Racão CCDR, $\mathrm{kg}$ ), Ganho Diário de Peso (GDP, $k g$ ) Conversão $\mathrm{Ali}$ mentar CCA de Suínos em Recria, Alimentados com Racóes Contendo Niveis Crescentes de Virginiamicina ${ }^{a}$.

\begin{tabular}{|c|c|c|c|c|c|c|}
\hline TRATAMENTO & BLOCOS & $\begin{array}{l}\text { PMI } \\
k g\end{array}$ & $\begin{array}{l}\text { PMF } \\
\mathrm{kg}\end{array}$ & $\begin{array}{l}\text { CDR } \\
\mathrm{kg}\end{array}$ & $\begin{array}{l}\text { GDP } \\
\mathrm{kg}\end{array}$ & CA \\
\hline & 1 & 10,80 & 25,15 & 0,98 & 0,513 & 1,92 \\
\hline T1 & 2 & 7.90 & 22.65 & 0.91 & 0.527 & 1.73 \\
\hline & 3 & 8,40 & 18,25 & 0.68 & 0.352 & 1.94 \\
\hline \multirow{4}{*}{$\begin{array}{l}\text { o ppm de } \\
\text { virginiamicina }\end{array}$} & 4 & 11,40 & 24,50 & 0,90 & 0.468 & 2,05 \\
\hline & 5 & 11,20 & 25,13 & 0,95 & 0,498 & 1.92 \\
\hline & 6 & 11,70 & 24,47 & 0.89 & 0.456 & 1.94 \\
\hline & Média & 10,23 & 23,36 & 0,90 & 0.469 & 1.92 \\
\hline \multirow{3}{*}{ Te } & 1 & 11,05 & 27,70 & 1,15 & 0,595 & 1,93 \\
\hline & 2 & 8,00 & 23,25 & 0,99 & 0,545 & 1.82 \\
\hline & 3 & 8,30 & 18,35 & 0,74 & 0,395 & 1.87 \\
\hline 25 ppm de & 4 & 12,00 & 27,85 & 1,18 & 0,566 & 2,08 \\
\hline \multirow{3}{*}{ virginiamicina } & 5 & 11,23 & 22,90 & 0,85 & 0,417 & 2,03 \\
\hline & 6 & 11,83 & 24,47 & 0,92 & 0.451 & 2,05 \\
\hline & Média & 10,40 & 24.25 & 0,97 & 0,495 & 1,96 \\
\hline \multirow{3}{*}{ T3 } & 1 & 10,70 & 28,65 & 1,03 & 0,570 & 1,81 \\
\hline & 2 & 8,00 & 20,75 & 0.82 & 0,455 & 1.81 \\
\hline & 3 & 8,35 & 19,40 & 0.74 & 0,395 & 1.88 \\
\hline 50 ppm de & 4 & 11,85 & 30,50 & 1,34 & 0,666 & 2,02 \\
\hline \multirow{3}{*}{ virginiamicina } & 5 & 11,53 & 26,63 & 1.02 & 0,539 & 1,89 \\
\hline & 6 & 11,90 & 20,20 & 0,94 & 0,511 & 1,84 \\
\hline & Média & 10,39 & 25,02 & 0,98 & 0,523 & 1.88 \\
\hline \multirow{3}{*}{ T4 } & 1 & 10.95 & 24,80 & 0,93 & 0,495 & 1.87 \\
\hline & 2 & 8,10 & 23,20 & 0,94 & 0.539 & 1,74 \\
\hline & 3 & 8,65 & 19,45 & 0.73 & 0,380 & 1.90 \\
\hline \multirow{4}{*}{$\begin{array}{l}75 \text { ppm de } \\
\text { virginiamicina }\end{array}$} & 4 & 11.85 & 28,85 & 1,08 & 0.607 & 1,78 \\
\hline & 5 & 11,56 & 26,63 & 0.99 & 0,539 & 1.83 \\
\hline & 6 & 12,00 & 20,90 & 0.98 & 0,532 & 1,84 \\
\hline & Média & 10,52 & 24.97 & 0.94 & 0.516 & 1,83 \\
\hline \multirow[b]{2}{*}{ IS } & 1 & 10,45 & 28,20 & 1.07 & 0,834 & 1.89 \\
\hline & 2 & 7,85 & 22,20 & 0,88 & 0,513 & 1,72 \\
\hline \multirow{4}{*}{$\begin{array}{l}100 \text { ppm de } \\
\text { virgíniamicina }\end{array}$} & 3 & 8,40 & 20,15 & 0.78 & 0,420 & 1,86 \\
\hline & 4 & 12,05 & 25,40 & 0,96 & 0,470 & 2.04 \\
\hline & 5 & 11.60 & 25,27 & 0,98 & 0.488 & 2.01 \\
\hline & $\frac{\theta}{\text { Média }}$ & $\begin{array}{l}11.87 \\
10.37\end{array}$ & $\begin{array}{l}26,57 \\
24,63\end{array}$ & $\begin{array}{l}0.94 \\
0.94\end{array}$ & $\begin{array}{l}0,525 \\
0.508\end{array}$ & $\begin{array}{l}1,79 \\
1.85\end{array}$ \\
\hline
\end{tabular}

avalores individuais representam a média de 2 blocos $1,2,3$, 4 a 3 animais unidade experimental tblocos 500 . 
54.

Tabela AZ - Componentes Sanguíneos CHematócrito e Hemoglobinas Plasmáticos CProteína Total, Albumina, Globulina, Rel Alb/glob. Uréia e Trigliceridias de Sulnos em Recria, Alimentados com Racbes Contendo Níveis Crescentes de Virgini amicina

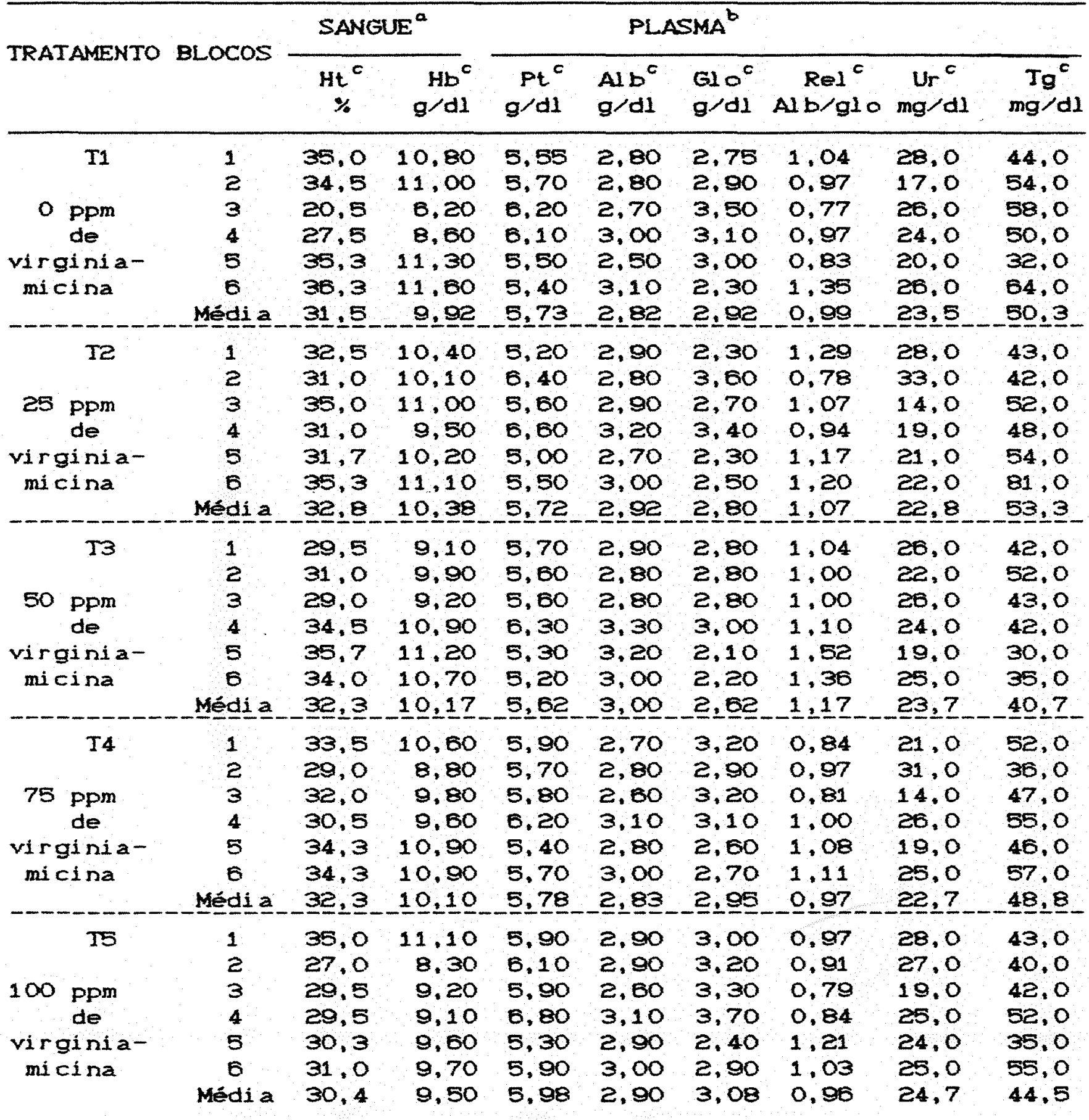

avalores individuais representam a modia de 2 (blocos 12,3 . 4 ) ou 3 animais unidade experimental (blocos 50 o.

valores individuais correspondom a amostras composias de plasma do 2 ou 3 ani mais /unidade experimental.

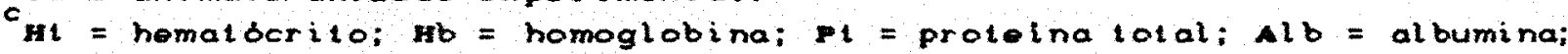
alo = globulina; nel Albralo = relacko albuminarglobulina: Ur = ureia. 